\title{
Research on Cooling Method in Surfacing Repair Process of Aero Compressor Blade
}

\author{
Shijie Dai $\mathbb{D},{ }^{1}$ Miao Gong $\mathbb{D}^{1},{ }^{1}$ Liwen Wang $\mathbb{D},{ }^{2}$ and Tao Wang $\mathbb{D}^{2}$ \\ ${ }^{1}$ School of Mechanical Engineering, Hebei University of Technology, Tianjin 300041, China \\ ${ }^{2}$ Institute of Aviation Engineering, Civil Aviation University of China, Tianjin 300300, China \\ Correspondence should be addressed to Miao Gong; mgong69@163.com
}

Received 25 October 2019; Revised 6 January 2020; Accepted 22 January 2020; Published 24 February 2020

Academic Editor: Alessandro Mauro

Copyright (c) 2020 Shijie Dai et al. This is an open access article distributed under the Creative Commons Attribution License, which permits unrestricted use, distribution, and reproduction in any medium, provided the original work is properly cited.

For the cooling method in surfacing repairing, most of the research focuses on the method based on the fixture structure. However, due to the low thermal conductivity and ultrathin alloy blade, the heat transfer speed from the molten pool to fixture is slow. When the heat is transferred to the fixture, most of the molten pool has solidified and absorbed or segregated out some impurities. Therefore, how to cool the welding area directly is more critical. For this reason, the thermal cycle characteristics of typical points of the blade and the heat transfer process of the key area of the fixture are analyzed, the original cooling time is calculated, and two innovative cooling methods based on lateral forced convection cooling and vertical jet impact forced convection cooling are proposed. For lateral forced cooling, with "AF-field" lateral convection cooling modeling, the cooling effects of characteristic points and sections under different flow velocities are calculated. For vertical jet impact cooling, the pressure, flow rate, and convective heat flux distribution on the wall under different impact heights and nozzle diameter are calculated. The influence of different inlet flow rates on cooling performance is influenced, based on the analysis results of impact modeling, the moving heat sink model is established, and the cooling effect under different heat sink-source distances is calculated. The heat transfer rules of two methods are analyzed in detail through modeling and simulations. The results show that both methods can improve the cooling effect and the vertical jet impact cooling method has an effect that is more obvious. When the nozzle radius is $2 \mathrm{~mm}$, the impact height is $4 d$, the inlet flow velocity is $35 \mathrm{~m} / \mathrm{s}$, and the distance is $7 \mathrm{~mm}$, and the cooling time under the vertical jet impact method is shortened by $12.5 \%$, which can achieve better cooling effect. The experiment further validates the effectiveness of the modeling and simulations.

\section{Introduction}

Compressor blades work in high temperature and high pressure for long time and often suffer from abrasion and defect, which affect flight safety. For abrasion or defect within $2 \mathrm{~mm}$, surfacing repair is currently an industryrecognized repair method [1]. Microbeam-pulsed plasma arc welding (MPAW) is a mainstream method for blade repair due to its excellent arc stability at low current, which makes it very suitable for welding ultrathin alloys [2, 3]. Compressor blades are mainly titanium alloy and nickel-based alloy blades. Titanium alloy have poor thermal conductivity and slow heat dissipation after welding. The use of inert gas protection cannot completely isolate the air, and the weld zone easily reacts with $\mathrm{C}, \mathrm{H}$, and $\mathrm{O}$ in the air to form impurities when the temperature is above $250^{\circ} \mathrm{C}$. These impurities have poor mechanical properties and are difficult to eliminate in postweld heat treatment, which is an important factor affecting welding quality.

Wang et al. [4] studied the influence of forced cooling conditions on the microstructure of TC4 friction stir welded joints and proposed a method of forced cooling by placing the whole clamp in a static dry ice ethanol mixture tank. Karimzadeh et al. [5] established a sequential coupled thermomechanical model based on the large displacement theory to study the welding of titanium alloy and found out the influence of heat input on the welding effect. For titanium alloy GTAW welding, the cooling rate is also the most 
important factor affecting the microstructure characteristics of the material [6, 7]. Manvatkar et al. [8] studied the cooling rate and peak temperature of friction stir welding. The results show that the welding quality can be effectively improved by controlling the peak temperature and cooling rate within a certain range. Sun et al. [9] compared the influence of three cooling conditions on the temperature field of electroslag welded joints by air cooling, copper cooling, and water-cooling analysis. They found that the high temperature residence time of electroslag welded joints could be greatly shortened by using forced cooling methods. Chunhua et al. [10] proposed a new method of local cooling auxiliary laser tailor welding for laser tailor welding and realized the local cooling of the heat-affected zone by adding a built-in runner auxiliary mechanism to the copper fixture. Manikandan et al. [11, 12] added a flow channel to the soldering pad, cooled the gold-tungsten argon arc welding process by liquid nitrogen, and studied the effects of different liquid nitrogen flow rates. Khalil et al. [13] proposed three-dimensional numerical simulation to quantify the design specifications of directional hot plate expansion channel heat exchangers (radiators). Under laminar flow condition, the number of spot welding, the diameter of spot welding, and the thickness of the fluid passage were changed to simulate the heat flow parameters, and the correctness of the model was verified by the experimental results. Fan et al. [14] proposed a new water-cooling system for K-TIG arc welding. A runner was machined under the welding table and water was flowed during welding. The experimental results show that the cooling system significantly reduces the pool volume and weld width.

The new engine compressor blades use ultrathin alloys with the partial tip thickness less than $1.5 \mathrm{~mm}$; the two main repair methods currently used are microplasma arc welding (MPAW) surfacing and laser cladding [15-17]. Compared to laser cladding, MPAW is one of the low-cost metals joining techniques for ultrathin alloy due to its inherent properties of controlling constricted arc with low-amperage current $[2,6]$. However, due to the structure of special flexible fixture, the distance between the water-cooling path and the flexible copper block is relatively far, and the cooling efficiency is a key problem in the MPAW welding process, especially in the second bead surfacing.

Based on the analysis of thermal cycle law and heat dissipation characteristics of the fixture for MPAW welding blade repair, this work proposes two new cooling methods. One is the argon lateral-forced convection cooling method and the other is the argon vertical jet impact forced convection cooling method. Then, calculate the cooling effect of the two cooling methods by modeling and simulation and verify the effectiveness by experiments. The research results are of great significance for the improvement of the welding repair process of ultrathin compressor blades.

\section{Heat Transfer Characteristics of the Fixture}

2.1. Flexible Fixture Model and Mesh Generation. The structure of flexible fixture used in the MPAW welding system is shown in Figure 1. The whole mechanism is

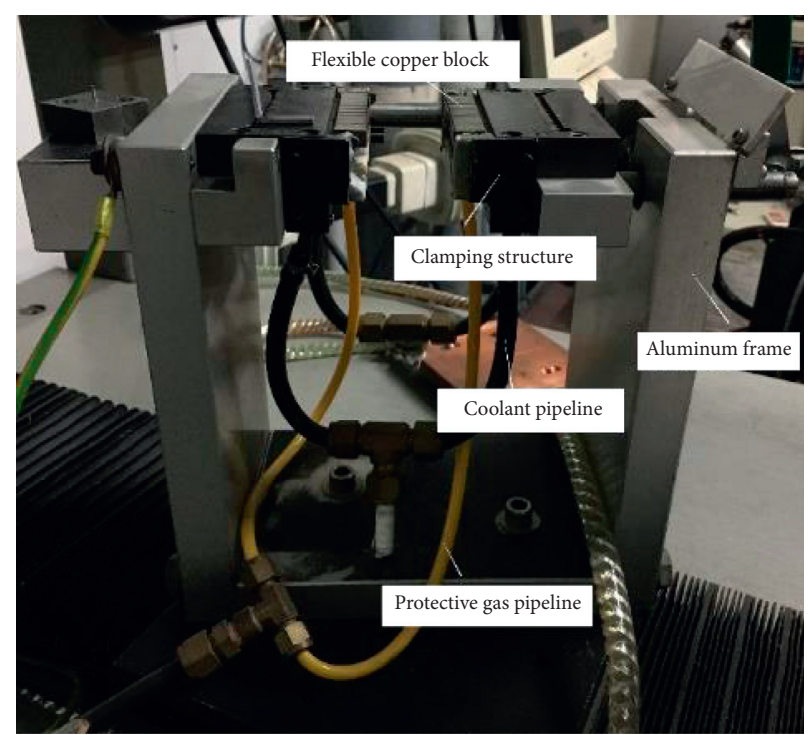

FIgURE 1: Fixture structure.

composed of aluminum base and copper heat dissipation clamping mechanism. The whole body has a symmetrical structure centered on the middle section of the clamping blade. The flexible copper block can achieve stable clamping of blades with smaller curvature. In order to simplify the calculation, the aluminum frame and the symmetrical part are removed, and a TC4 test piece model with a size of $65 \mathrm{~mm} \times 30 \mathrm{~mm} \times 1 \mathrm{~mm}$ was added to simulate the ultrathin compressor blade.

COMSOL multiphysics is used to analyze the multiphysical field coupling phenomenon of the thermal field and flow field. The heat transfer module and CFD module in COMSOL are selected to establish the finite element model. Dense meshes are applied on the surface of the test piece and the front end of the copper blocks, and loose meshes are applied on the top of the copper blocks. The mesh consists of 132,843 elements in total, of which the minimum element size is $1.79 \times 10^{-5} \mathrm{~m}$, the maximum element size is $4.92 \times 10^{-3} \mathrm{~m}$, and the average mesh mass is 0.6541 . The simplified finite element model of the mechanism and the mass distribution of the meshes are shown in Figure 2.

The central molten pool of the test piece was taken as the verification object. The maximum temperature of the central molten pool of the test piece under different numbers of mesh is calculated, as shown in Table 1. It can be seen that when the number of mesh is more than 132,843, the temperature of the molten pool changes little. Therefore, in order to reduce the amount of calculation, the number of mesh is selected to be 132843 . The step independent calculation results is shown in Table 2. Similarly, the time step is selected to be 0.1 .

2.2. Boundary Conditions and Assumptions. During the surfacing process, the blade undergoes a severe physical and chemical reaction with strong nonlinearity. In order to simplify the model and improve convergence, the model's boundary conditions and assumptions are as follows: 


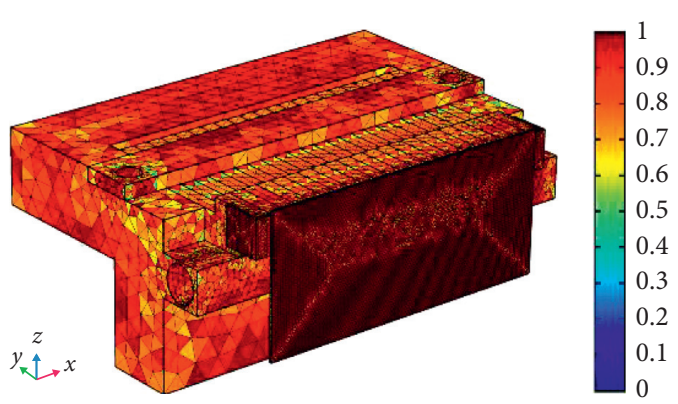

Figure 2: Simplified finite element model and mesh mass distribution.

TABLe 1: Mesh independence calculation results.

\begin{tabular}{llllll}
\hline Mesh number & 66680 & 96547 & 132843 & 165917 & 205074
\end{tabular}

\begin{tabular}{llllll} 
Temperature $\left({ }^{\circ} \mathrm{C}\right)$ & 1780.2 & 1792 & 1801.4 & 1806 & 1804.2 \\
\hline
\end{tabular}

TABLE 2: Step independent calculation results.

\begin{tabular}{lcccc}
\hline Time step $(\mathrm{s})$ & 0.2 & 0.1 & 0.08 & 0.05 \\
Temperature $\left({ }^{\circ} \mathrm{C}\right)$ & 1787 & 1801.4 & 1800 & 1805 \\
\hline
\end{tabular}

(1) The initial temperature of the model is $20^{\circ} \mathrm{C}$. The natural convection heat dissipation between the entire fixture and the air is $20 \mathrm{~W} /\left(\mathrm{m}^{2} \cdot \mathrm{K}\right)$. The thermal insulation surface is the symmetry plane on the test piece.

(2) The copper bond is in close contact with each other, and the copper bond is in close contact with the test piece.

(3) Ignore the evaporation and convection of the molten pool. Ignore the droplet transfer and the latent heat of fusion of the welding wire.

(4) It is assumed that the material of clamp and test piece is isotropic and continuous.

2.3. Welding Thermal Cycle Analysis. The transient solver and the direct solver PARDISO are used to solve the partial differential equation of the model, and set the presorting algorithm as the multithread nesting analysis method. During the welding process, when the heat source moves along the test piece, the temperature of each point on the surface rises first and then decreases with time. As shown in Figure 3, five feature points with a spacing of $10 \mathrm{~mm}$ are taken along the centerline of the weld, and three feature points with a spacing of $0.2 \mathrm{~mm}$ are taken along the vertical welding direction. According to the previous study of the pulse heat source model [18], the calculated thermal cycle curve is shown in Figure 4. The results show that the points $a-, a, b, c$, and $c+$ are all in the quasi-steady state of the welding process, and the shape of the thermal cycle curve is consistent. The maximum temperature of the molten pool is about $1800^{\circ} \mathrm{C}$.

Since the thickness of the alloy used in this study is $1 \mathrm{~mm}$, the symmetrical half thickness is taken and the $0.2 \mathrm{~mm}$ is used as the characteristic point interval, which is very close to the center of the weld. It is difficult to distinguish the difference of the thermal cycle curve by the whole curve, so the time interval of the intercepting high temperature period is $24 \mathrm{~s}-16.5 \mathrm{~s}$ and the time step is $0.01 \mathrm{~s}$. The calculation results show that the difference between point $e$ and $b$ in the high temperature section is small. This is because the distance between the two points is only $0.2 \mathrm{~mm}$, so the temperature changes little. However, the difference between point $f$ and point $b$ far from the weld center is obvious. The calculation results verified the basic rule of the thermal cycle curve.

Figure 4(c) is the thermal cycle curve of characteristic point $b$. The time interval is $22.5 \mathrm{~s}-28 \mathrm{~s}$ and the time step is $0.1 \mathrm{~s}$. As the welding heat source approached the central point $b$, the temperature began to rise. When the welding proceeded to $24.68 \mathrm{~s}$, the temperature reached about $1650^{\circ} \mathrm{C}$ and the material began to melt and form a molten pool. When the welding time was $25 \mathrm{~s}$, the center of the heat source reached the center point. However, the temperature of the molten pool did not reach the maximum temperature at this time. Because the moving heat source area is actually a double elliptical shape, when the heat source center reached the center point, the essence was that the maximum heat flux density of the heat source acted at the center point, so it did not reach the maximum temperature. As the heat source continued to move forward, the temperature continued to rise. When the welding time was $25.2 \mathrm{~s}$, the molten pool reached a maximum temperature of about $1800^{\circ} \mathrm{C}$, and then the molten pool entered the cooling stage. When the temperature dropped to about $1650^{\circ} \mathrm{C}$ at $25.68 \mathrm{~s}$, the pool began to solidify and the weld bead began to form. When the pool was continuously cooled to $27.89 \mathrm{~s}$, the temperature dropped to about $250^{\circ} \mathrm{C}$. Thereafter, the temperature has little effect on the structure and properties of the weld bead. According to the calculation results, the cooling time from the maximum temperature of the molten pool to the time of cooling to $250^{\circ} \mathrm{C}$ of the thermal cycle of natural cooling welding is about $2.69 \mathrm{~s}$ in the natural cooling welding process.

2.4. Analysis of Fixture Water Cooling Effect. Referring to the relevant manual, the recommended flow rate for forced convection heat transfer in the smooth inner wall pipeline with liquid refrigerant is $1 \sim 2 \mathrm{~m} / \mathrm{s}$. So, set $3 \mathrm{~L} / \mathrm{min}, 5 \mathrm{~L} / \mathrm{min}$, and $6 \mathrm{~L} / \mathrm{min}$ to analyze the cooling effect. The corresponding flow rate is $0.99 \mathrm{~m} / \mathrm{s}, 1.66 \mathrm{~m} / \mathrm{s}$, and $1.99 \mathrm{~m} / \mathrm{s}$. According to the calculation result of formula (1), the corresponding Re is $\operatorname{Re}=6093.2, \operatorname{Re}=10155$, and $\operatorname{Re}=12186$. Considering the flow characteristics of the water cooling path of MPAW fixture and the relationship between Re and turbulence [19], the coupled field of the heat flow is simulated and analyzed by using the $k-\varepsilon$ model. The relationship between turbulent energy and turbulent energy dissipation rate is expressed as follows:

$$
\varepsilon=0.09 \rho \frac{k^{2}}{\mu}\left(\frac{\mu_{t}}{\mu}\right)^{-1},
$$

where $\mu_{t} / \mu$ is the turbulent viscosity ratio, which is proportional to the Re. 


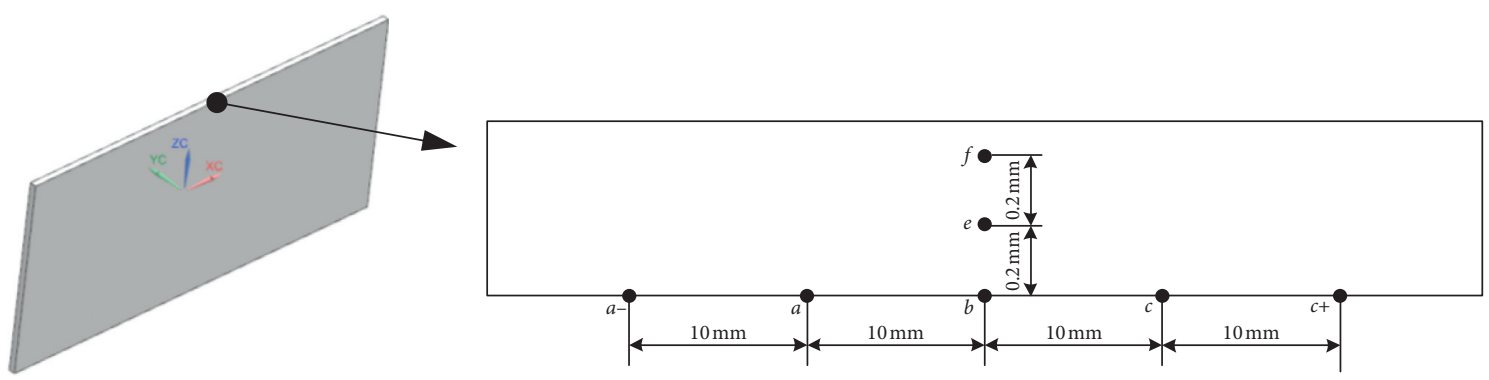

FIGURE 3: Location of the thermal cycle feature point.

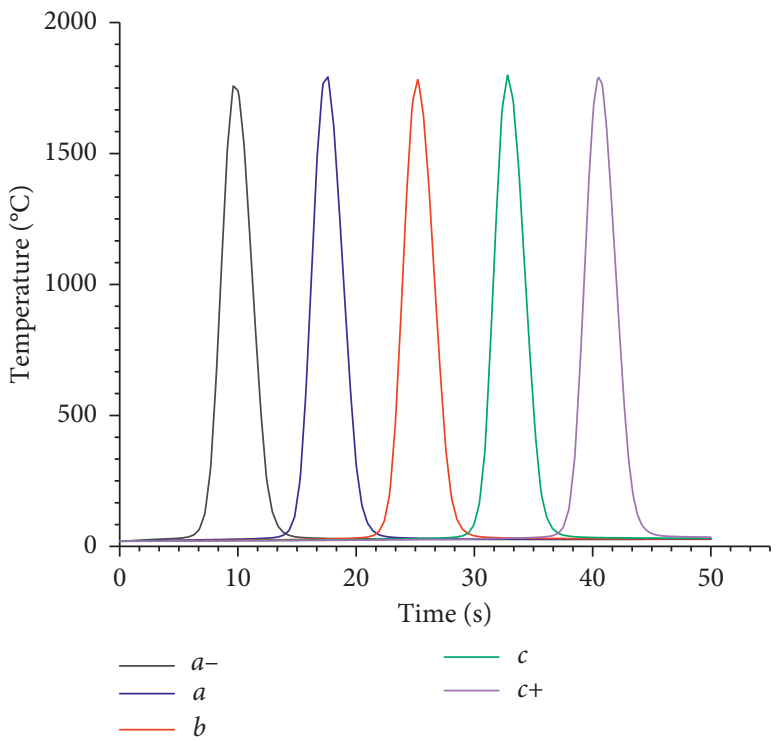

(a)
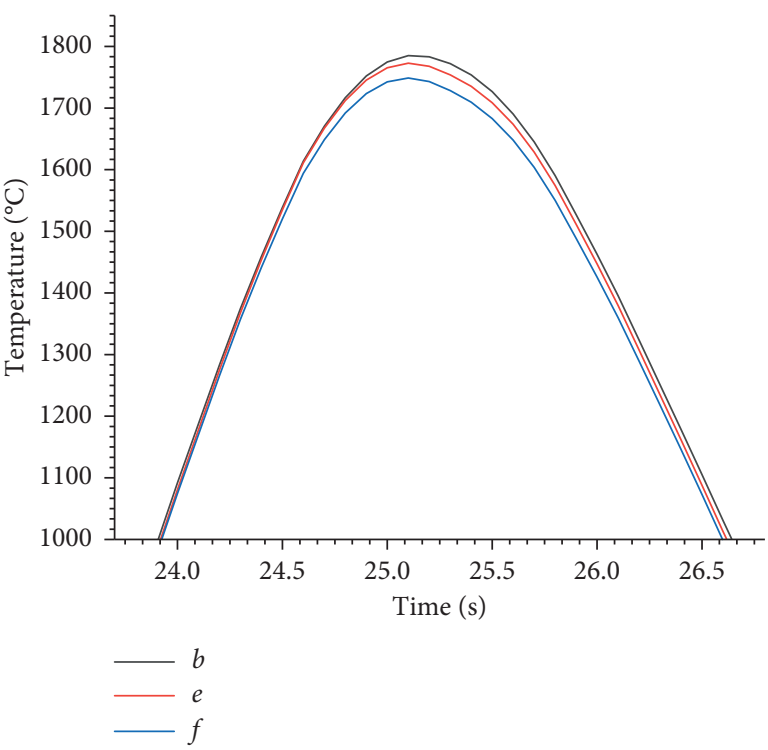

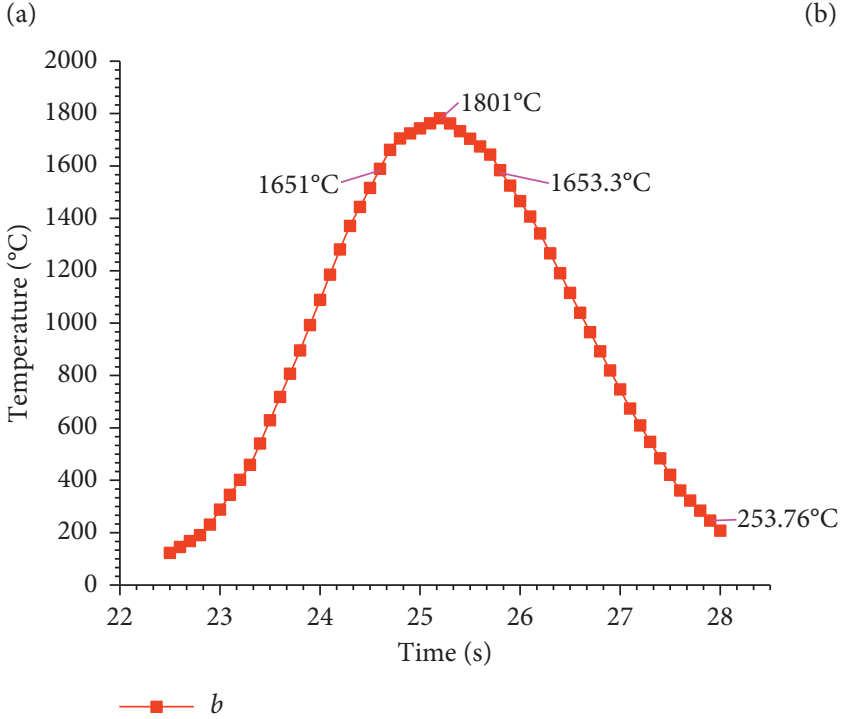

(c)

Figure 4: Thermal cycle curve of the characteristic point: (a) longitudinal feature point thermal cycle curve; (b) transverse feature point thermal cycle curve; (c) thermal cycle curve of point $b$. 
The transport equation with $k$ and $\varepsilon$ as unknowns is

$$
\begin{aligned}
\frac{\partial(\rho k)}{\partial t}+\frac{\partial\left(\rho k u_{i}\right)}{\partial x_{i}}= & \frac{\partial}{\partial x_{j}}\left[\left(\mu+\frac{\mu_{t}}{\sigma_{k}}\right) \frac{\partial k}{\partial x_{j}}\right]+G_{k}-\rho \varepsilon, \\
\frac{\partial(\rho \varepsilon)}{\partial t}+\frac{\partial\left(\rho \varepsilon u_{i}\right)}{\partial x_{i}}= & \frac{\partial}{\partial x_{j}}\left[\left(\mu+\frac{\mu_{t}}{\sigma_{\varepsilon}}\right) \frac{\partial \varepsilon}{\partial x_{j}}\right] \\
& +C_{1 \varepsilon} \frac{\varepsilon}{k} G_{k}-C_{2 \varepsilon} \rho \frac{\varepsilon^{2}}{k}
\end{aligned}
$$

where $C_{1 \varepsilon}$ and $C_{2 \varepsilon}$ are empirical constants and $G_{k}$ is turbulent energy generation; its expansion is

$$
\begin{aligned}
G_{k}= & \mu_{t}\left\{2\left[\left(\frac{\partial u}{\partial x}\right)^{2}+\left(\frac{\partial v}{\partial y}\right)^{2}+\left(\frac{\partial w}{\partial z}\right)^{2}\right]+\left(\frac{\partial u}{\partial y}+\frac{\partial v}{\partial x}\right)^{2}\right. \\
& \left.+\left(\frac{\partial u}{\partial z}+\frac{\partial w}{\partial x}\right)^{2}+\left(\frac{\partial v}{\partial z}+\frac{\partial w}{\partial y}\right)^{2}\right\} .
\end{aligned}
$$

In this study, set the relevant model parameters to $C_{1 \varepsilon}=1.44$ and $C_{2 \varepsilon}=1.92$. The turbulence intensity $I$ is as follows:

$$
I=\frac{u^{\prime}}{\bar{u}}=0.16(\mathrm{Re})^{-1 / 8} \text {. }
$$

After calculation, intercept the cooling time to $250^{\circ} \mathrm{C}$ and compare different flow rates with natural cooling, as shown in Figure 5.

The results show that the cooling time decreases with the increase of the flow rate in the recommended range, but the overall difference is not significant.

Select the middle section of the fixture as the object of analysis when the heat source moves to the middle position of the specimen. The temperature distribution and isotherm of the fixture are shown in Figure 6.

It can be seen from Figure 6 that the temperature of the corners of the flexible gasket and the copper block that are in contact with the test piece is the highest, about $113^{\circ} \mathrm{C}$, the isotherm is dense, and the temperature gradient is large. However, the heat source has little effect on the position of the flow path, just about $25^{\circ} \mathrm{C}$. It can be inferred that due to the long distance between the flow path position and the contact point, the heat conductivity of leaves is low and the amount of heat arrived per unit time is less. Hiding the test piece and gasket, the temperature field transient distribution of clamping part is as shown in Figure 7.

The results show that the temperature of the copper block near the welding heat source is higher, and the maximum temperature is above $76^{\circ} \mathrm{C}$. Therefore, the argon-forced convection cooling method can be considered to accelerate the heat dissipation near the contact surface between the copper block and the specimen, thereby enhancing the heat conduction between the blade and the clamp.

\section{Lateral-Forced Convection Cooling Method}

3.1. Lateral-Forced Convection Cooling Model. The forced argon can accelerate the loss of heat from the surface of the

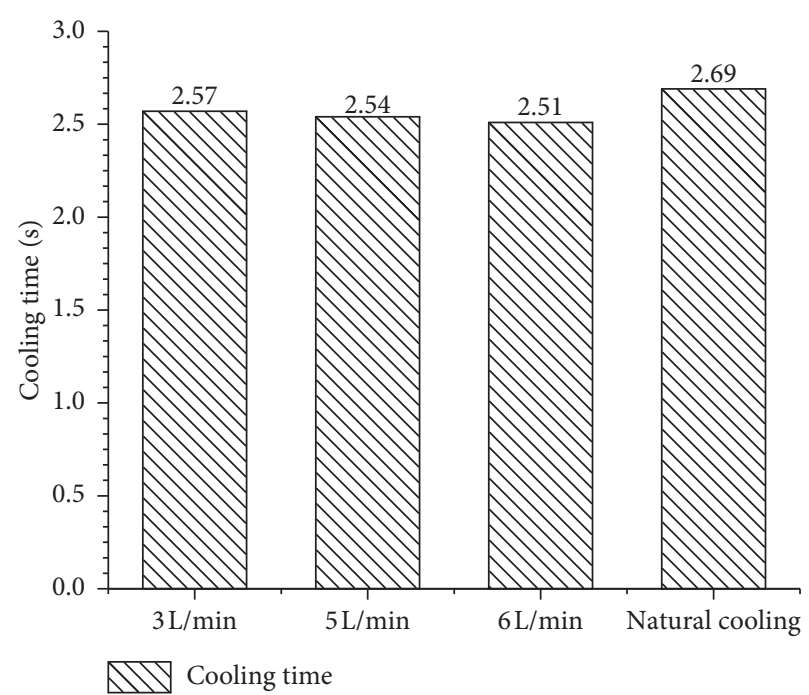

FIgURE 5: Comparison of cooling time between different flow velocities and natural cooling.

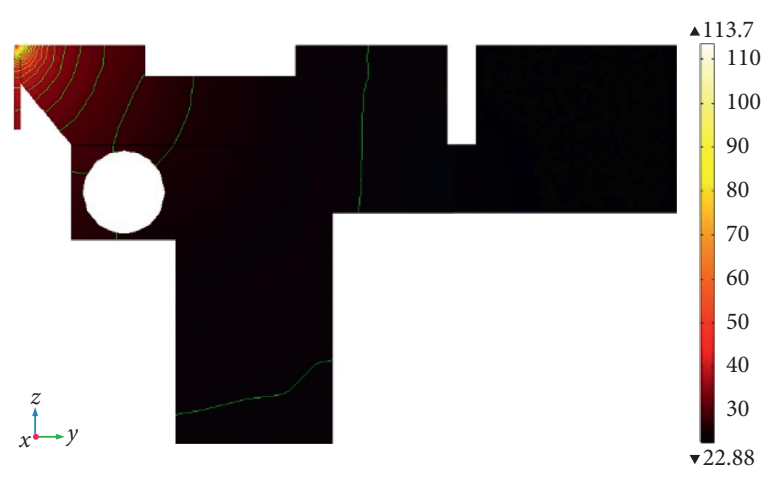

FIgURE 6: Temperature field distribution of the section in the fixture $\left({ }^{\circ} \mathrm{C}\right)$.

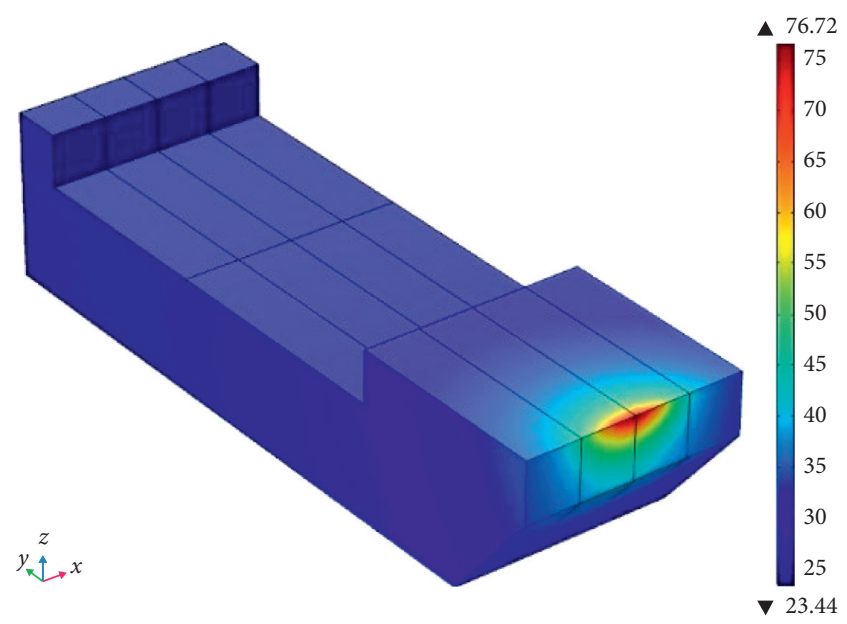

FIgURE 7: Temperature field transient distribution of the clamping part $\left({ }^{\circ} \mathrm{C}\right)$.

fixture to the environment, which in turn enhances heat transfer between the blade and the fixture, thereby increasing cooling efficiency. Lateral-forced convection 
cooling uses argon as the cooling medium, in order to establish a high-precision heat flow coupling model and avoid the definition of abstract substances in simulation. The material properties of argon are defined in the three-dimensional structure of "argon flow field" (hereinafter referred to as AF-filed) so that the flow direction of the AFfiled just covers the upper surface of the array copper block, and the finite element model of the fixture is shown in Figure 8.

The mesh of the AF-filed model along the wall boundary layer and near the high temperature part of the fixture is denser; the mesh of the rest part is looser. The AF-filed consists of 22706 elements, with an average mesh mass of 0.619. Among them, the number of boundary layers is 5 , the stretching factor of boundary layer is 1.2 , and the thickness adjusting factor is 1 . The whole model consists of 165047 mesh cells.

To avoid the welding heat source, set the edge of AF-filed $1 \mathrm{~mm}$ away from the test piece. In addition, in order to avoid bringing the heat radiated by the heat source back to the area after welding, the lateral flow direction should be the same as the moving direction of the welding heat source. So, the right side of the AF-field model is defined as the argon inlet, the initial temperature is $20^{\circ} \mathrm{C}$, and the left side is the outlet.

3.2. Mass, Momentum, and Energy Conservation Equations. Argon is a weakly compressible gas, and its density is a variable, which is unsteady flow. Taking a microelement in the fluid domain as the research object, the argon flowing through the microelement in the time interval $\mathrm{d} \tau$ meets the law of mass conservation, which is expressed as follows:

$$
\frac{\partial \rho}{\partial \tau}+\frac{\partial(\rho u)}{\partial x}+\frac{\partial(\rho v)}{\partial y}+\frac{\partial(\rho \omega)}{\partial z}=0,
$$

where $\rho$ is the density of argon and $u, v$, and $w$ are the velocity components of argon in $x, y$, and $z$ directions.

According to the law of conservation of momentum, for unsteady weakly compressible fluid, the following equations of motion should be satisfied:

$$
\rho \frac{D \mathbf{V}}{D \tau}=\rho \mathbf{F}-\nabla p+\nabla \cdot 2 \mu[\varepsilon]-\frac{2}{3} \mu \nabla \operatorname{div} \mathbf{V},
$$

where $\mathbf{V}$ is the argon velocity vector, $\mathbf{F}$ is the volume force of the microelement, $p$ is the surface force of the microelement, $[\varepsilon]$ is the fluid deformation tensor, and $D \mathbf{V} / D \tau$ is the total derivative of the velocity vector to time.

For incompressible fluid with constant viscosity coefficient, the abovementioned formula can be simplified as follows:

$$
\left\{\begin{array}{l}
\rho\left(\frac{\partial u}{\partial \tau}+u \frac{\partial u}{\partial x}+v \frac{\partial u}{\partial y}+w \frac{\partial u}{\partial z}\right)=F_{x}-\frac{\partial p}{\partial x}+\eta\left(\frac{\partial^{2} u}{\partial x^{2}}+\frac{\partial^{2} u}{\partial y^{2}}+\frac{\partial^{2} u}{\partial z^{2}}\right) \\
\rho\left(\frac{\partial v}{\partial \tau}+u \frac{\partial v}{\partial x}+v \frac{\partial v}{\partial y}+w \frac{\partial v}{\partial z}\right)=F_{y}-\frac{\partial p}{\partial y}+\eta\left(\frac{\partial^{2} v}{\partial x^{2}}+\frac{\partial^{2} v}{\partial y^{2}}+\frac{\partial^{2} v}{\partial z^{2}}\right) \\
\rho\left(\frac{\partial w}{\partial \tau}+u \frac{\partial w}{\partial x}+v \frac{\partial w}{\partial y}+w \frac{\partial w}{\partial z}\right)=F_{z}-\frac{\partial p}{\partial z}+\eta\left(\frac{\partial^{2} w}{\partial x^{2}}+\frac{\partial^{2} w}{\partial y^{2}}+\frac{\partial^{2} w}{\partial z^{2}}\right)
\end{array}\right.
$$

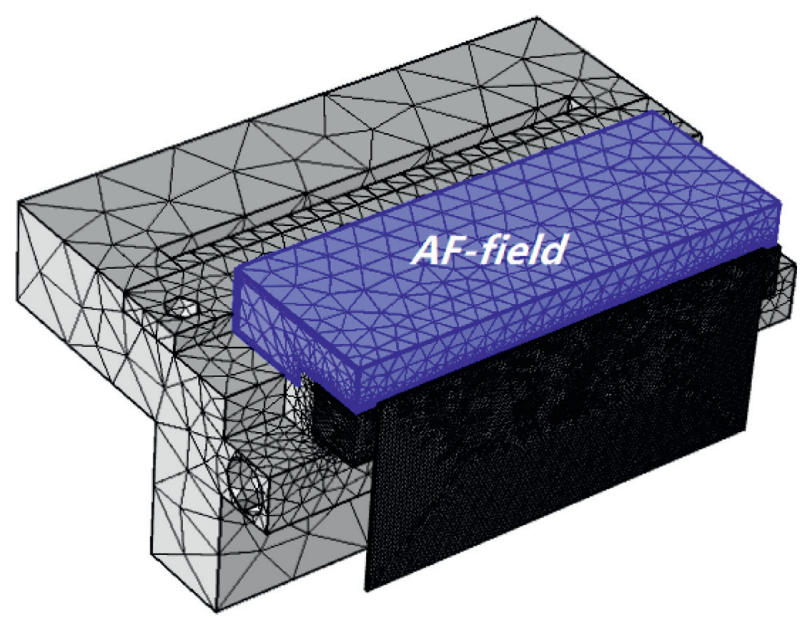

FIgURE 8: Finite element model of the lateral convection fixture cooling system.

where $\eta$ is the dynamic viscosity and $F_{x}, F_{y}$, and $F_{z}$ are the components of the volume force in the three directions of $x$, $y$, and $z$.

According to the first law of thermodynamics, the energy equation of the argon flow can be obtained:

$$
\frac{\partial T}{\partial \tau}+u \frac{\partial t}{\partial x}+v \frac{\partial t}{\partial y}+w \frac{\partial t}{\partial z}=\frac{k}{\rho c_{p}}\left(\frac{\partial^{2} t}{\partial x^{2}}+\frac{\partial^{2} t}{\partial y^{2}}+\frac{\partial^{2} t}{\partial z^{2}}\right)+S_{T},
$$

where $t$ is the thermodynamic temperature of the fluid and $S_{T}$ is the viscous dissipation term.

3.3. Model Parameter Calculation. When argon blows across the upper surface of the fixture, the flow pattern will gradually change from laminar flow to turbulent flow, maintain laminar flow before a certain critical distance $x_{c}$, and then gradually change to turbulent flow after this distance. Generally, the critical Reynolds number is $\operatorname{Re}_{c}=5 \times 10^{5}$, and the initial velocity $u_{\infty}=4 \mathrm{~m} / \mathrm{s}$. The Reynolds number and Prandtl number of argon at $x_{c}$ are characterized as follows:

$$
\begin{aligned}
\operatorname{Re}_{x} & =\frac{u_{\infty} \cdot x_{c}}{v}, \\
P_{r} & =\frac{v}{a},
\end{aligned}
$$

where $u_{\infty}$ is the initial velocity of the argon center and $v$ and $a$ are the dynamic viscosity and thermal diffusion coefficients of the fluid, respectively. So, $x_{c}$ can be expressed as follows:

$$
x_{c}=\frac{\operatorname{Re}_{c} \cdot v}{u_{\infty}} \text {. }
$$

After calculation, $x_{c}=1.46 \mathrm{~m}$, greater than "AF-field" length, so select " $k-\omega$ " in the lateral model.

The welding process is a transient process. The heat source moves along the welding direction and the hightemperature zone on the fixture changes with time. Therefore, the surface cooling of argon side-blown fixture 
belongs to the problem of sweeping nonisothermal plate heat transfer, which is approximated to the plate heat transfer without the initial heat transfer section. From the beginning of the air domain $x=\xi(t)$ to the high temperature zone of the fixture, the wall temperature is $T_{\omega}$, the initial section is room temperature, and when the argon flows through the upper surface of the fixture, a velocity boundary layer is formed at the beginning. There are no heat exchange and thermal boundary layers in the range of $0 \sim \xi(t)$. The velocity distribution in the boundary layer of the adhering velocity can be expressed as follows:

$$
\begin{gathered}
\frac{u}{u_{\infty}}=\frac{3}{2} \eta-\frac{1}{2} \eta^{3}, \\
\eta=\frac{y}{\delta(x)},
\end{gathered}
$$

where $\delta(x)$ is the boundary layer thickness of the fixture surface velocity from the front end $x$.

Similarly, the temperature distribution in the thermal boundary layer is

$$
\begin{gathered}
\frac{T-T_{\omega}}{T_{\infty}-T_{\omega}}=\frac{3}{2} \eta_{T}-\frac{1}{2} \eta_{T}^{3}, \\
\eta_{T}=\frac{y}{\delta_{T}},
\end{gathered}
$$

where $\delta_{T}$ is the thickness of the thermal boundary layer.

From the boundary layer energy integral equation, the rate of change in enthalpy thickness is equal to the Stanton number (St), i.e.,

$$
\frac{\mathrm{d} \delta_{i}}{\mathrm{~d} x}=\mathrm{St}=\frac{1.5 a}{u_{\infty} \delta_{T}} .
$$

Substituting formulas (11) and (13) into enthalpythickness definition formula is

$$
\begin{aligned}
\delta_{i} & =\int_{0}^{\delta_{T}}\left(\frac{3}{2} \eta-\frac{1}{2} \eta^{3}\right)\left(1-\frac{3}{2} \eta_{T}+\frac{1}{2} \eta_{T}^{3}\right) \\
d y & =\delta \overline{\delta_{T}}\left(\frac{3}{20} \overline{\delta_{T}}-\frac{3}{280} \overline{\delta_{T}^{3}}\right),
\end{aligned}
$$

where $\overline{\delta_{T}}=\delta_{T} / \delta<1$

Substituting formula (16) into formula (15), we obtain

$$
4 \overline{\delta_{T}} x \frac{\mathrm{d} \overline{\delta_{T}}}{\mathrm{~d} x}+\overline{\delta_{T}^{3}}=\frac{0.929}{\operatorname{Pr}} .
$$

Apply boundary conditions when $x=\xi(t), \overline{\delta_{T}}=0$, then

$$
\overline{\delta_{T}}=\frac{\operatorname{Pr}^{-1 / 3}}{1.025}\left[1-\left(\frac{\xi(t)}{x}\right)^{3 / 4}\right]^{1 / 3} .
$$

The $\mathrm{Nu}$ of argon from the front end $x$ can be expressed as follows:

$$
\mathrm{Nu}_{x}=0.331 \sqrt{\operatorname{Re}_{x}} \operatorname{Pr}^{1 / 3} \frac{1}{\left[1-(\xi(t) / x)^{3 / 4}\right]^{1 / 3}} .
$$

$\mathrm{Nu}$ is used to characterize the convective heat transfer strength. The surface heat transfer coefficient obtained from the abovementioned formula is

$$
h_{x}=\frac{\mathrm{Nu}_{x} \cdot k}{l},
$$

where $k$ is the thermal conductivity of argon and $l$ is the characteristic length of the air domain.

3.4. Boundary Conditions. The heat transfer characteristics of the fixture are heat-flow coupled conjugate heat transfer, so the boundary conditions are divided into two types: fluid boundary conditions and solid boundary conditions.

The fluid region in the model is the air region through which argon flows. The fluid boundary conditions are

(1) The initial temperature of argon is $20^{\circ} \mathrm{C}$

(2) The fluid inlet is the right end of the air domain, the velocity boundary condition is adopted, and the normal inflow velocity is $4 \mathrm{~m} / \mathrm{s}$

(3) The fluid outlet is the left end of the air domain, the pressure boundary condition is adopted, and the outlet pressure is set to $0 \mathrm{~Pa}$ to suppress the reflux

(4) The air domain adopts a wall boundary condition without slip

The solid region is the part outside the fluid region. The solid boundary conditions are

(1) The initial temperature of the solid model is set to $20^{\circ} \mathrm{C}$

(2) The symmetry plane of the TC4 test piece is set to thermal insulation

(3) Applying a moving heat flux to the upper surface of the TC4 test piece as a double elliptical moving heat source

(4) The whole model is set as natural convection with the surrounding environment

(5) High-temperature areas such as test pieces and copper blocks are set as heat radiation surfaces

3.5. Thermal Flow-Coupled Field Analysis. The transient solver and the PARDISO solver are used to solve the model. The flow field affects the solid temperature field distribution through convective heat transfer. At the same time, the temperature field affects the thermal properties of argon, which affects the velocity distribution and temperature distribution of the flow field and hides the solid part of the model, showing only the fluid area.

As shown in Figure 9, the flow velocity distribution of the airflow field is at $25 \mathrm{~s}$ and the density of the streamline and the color depth indicate the velocity field distribution of the fluid. Five sections are selected, and the color of the section is shown as the flow velocity distribution on the section. The initial average velocity of the right-end inlet of the air domain is $4 \mathrm{~m} / \mathrm{s}$. It can be seen from the figure that the initial section velocity is approximately $4 \mathrm{~m} / \mathrm{s}$ and the velocity 


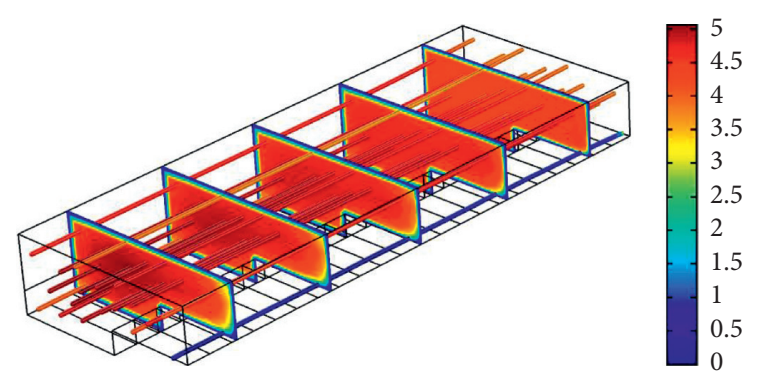

Figure 9: Flow field velocity distribution $(\mathrm{m} / \mathrm{s})$.

distribution on the section is relatively uniform. The velocity of the adherent boundary layer is $0 \mathrm{~m} / \mathrm{s}$, and the thickness of the boundary layer is thinner. Due to the development of the flow, it can be seen from the initial section to the development section that the cut surface and the streamline are gradually deepened, and the maximum velocity in the development section is about $5 \mathrm{~m} / \mathrm{s}$. At the same time, the velocity distribution of the cut surface shows a large flow velocity in the middle region, while the flow velocity in the near-wall viscous bottom region is small, and the thickness of the boundary layer becomes thicker, which conforms to the laminar flow development law.

Select five sections at $25 \mathrm{~s}$. The temperature distribution of the flow field is shown in Figure 10. It can be seen that the temperature of the flow field near the moving heat source is higher, the maximum temperature is around $76^{\circ} \mathrm{C}$, and the temperature far away from the heat source is close to room temperature.

In order to observe the isotherm difference more clearly, Figure $10(\mathrm{~b})$ is a schematic diagram of the temperature distribution displayed by the isotherm. It can be seen that the temperature distribution in the high-temperature region of the flow field also exhibits a semielliptical shape along the welding direction. Due to the influence of the flow rate of argon, the temperature of the left section is slightly higher than that of the right section. The high temperature is mainly concentrated near the test piece, and the temperature is weakened from the center of the ellipse to the edge.

In order to further study the influence of the flow field temperature in the welding process by the moving heat source, the middle section of the AF-field, that is, the air domain cut surface of $x=0.0325 \mathrm{~m}$, is selected to observe the temperature distribution of the middle section at different times.

The temperature distribution of the cross section in the AF-field at different times is shown in Figure 11. Since the welding heat source is moving, the heat source center moves to the middle section at $25 \mathrm{~s}$. Therefore, 6 time points were selected for analysis and comparison in the interval of $5 \mathrm{~s}$ before and after $25 \mathrm{~s}$. It can be seen from the figure that at $15 \mathrm{~s}$, the center of the welding heat source has not moved to the middle section.

Meanwhile, by calculating the time and the moving speed, the distance between the heat source center and the middle section is $13 \mathrm{~mm}$. Due to the long distance, the heat transfer of the molten pool to the middle section is small, so the temperature distribution of the middle section is weakly affected by the heat source. The temperature in the AF-field near the corner of the copper block is the highest, but just reaching about $26^{\circ} \mathrm{C}$. At the time of $20 \mathrm{~s}$, the distance between the heat source and the middle section is $6.5 \mathrm{~mm}$. Compared with $15 \mathrm{~s}$, the heat transfer from the molten pool to the middle section increases slightly. The temperature of the middle section is affected by the heat source, and the high temperature area is more concentrated. The highest temperature at the corner of the copper block of the AF-field section rises to about $31^{\circ} \mathrm{C}$. When $25 \mathrm{~s}$, the center of the welding heat source reaches the middle section of AF-field, and the temperature gradient is the largest, with the maximum temperature of about $73^{\circ} \mathrm{C}$. Because of the maximum heat concentration, the temperature distribution in the middle section shows that the color difference at the corner is the largest, while the color of the rest is uniform. At $30 \mathrm{~s}$, the center of the heat source leaves the middle section, at a distance of $6.5 \mathrm{~mm}$ in front of it. The temperature of the middle section decreases, the influence of heat source decreases, and the maximum temperature drops to about $34^{\circ} \mathrm{C}$, which is slightly higher than $20 \mathrm{~s}$ with the same distance. This is because the lateral airflow inevitably brings the residual heat of the solidification of the molten pool to the middle section so that the section temperature is slightly increased. Similarly, the temperature at $35 \mathrm{~s}$ is higher than $15 \mathrm{~s}$, and it is found that the thickness of the thermal boundary layer near the edge of the copper block becomes larger. At $40 \mathrm{~s}$, the maximum temperature is reduced to about $27^{\circ} \mathrm{C}$, the thickness of the thermal boundary layer continues to increase, and the temperature diffusion is more obvious, indicating that argon still plays a role of continuous cooling.

\subsection{Cooling Effect Analysis}

3.6.1. Contrast with Natural Cooling. By analyzing the thermal cycle curve under the lateral-forced convection cooling of argon, it is found that the method can accelerate the heat dissipation speed to a certain extent and reduce the cooling time compared with the natural cooling. Since the shape of the molten pool in the welding process reaches the quasi-steady state in the middle of the test piece, the research focuses on the middle section of the test piece. Three sections of the test piece were selected at intervals of $10 \mathrm{~mm}$ in the welding direction to analyze and compare the maximum temperature. Hide the fixture part and show only the test piece. With lateral-forced convection cooling mothed, the temperature distribution at $17.63 \mathrm{~s}, 25.21 \mathrm{~s}$, and $32.78 \mathrm{~s}$ of the three sections is as shown in Figure 12.

The maximum temperature of the molten pool of the left section is $1785^{\circ} \mathrm{C}$, of the middle section is $1787^{\circ} \mathrm{C}$, and of the right section is $1782^{\circ} \mathrm{C}$. The numerical value fluctuates in the allowed error range, which is less than the maximum temperature of the molten pool under natural cooling.

Three feature points $a, b$, and $c$ on the test piece are selected, and the thermal cycle curves of the three points are obtained by calculating the coupled model. The time range is from the highest temperature to $250^{\circ} \mathrm{C}$ and the time step is $0.1 \mathrm{~s}$. The cooling effect of the three points is obtained, as 


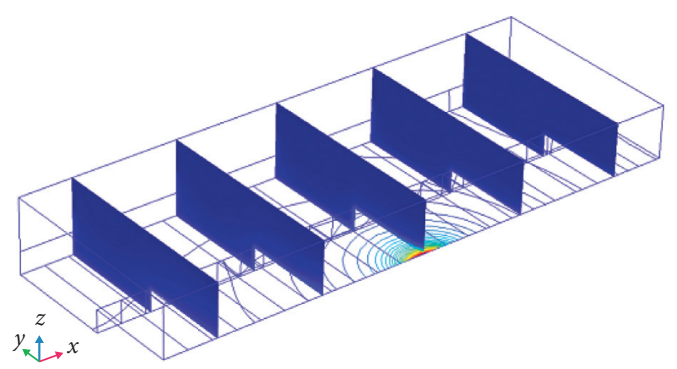

(a)

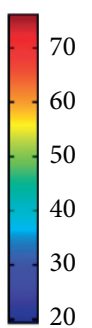

20

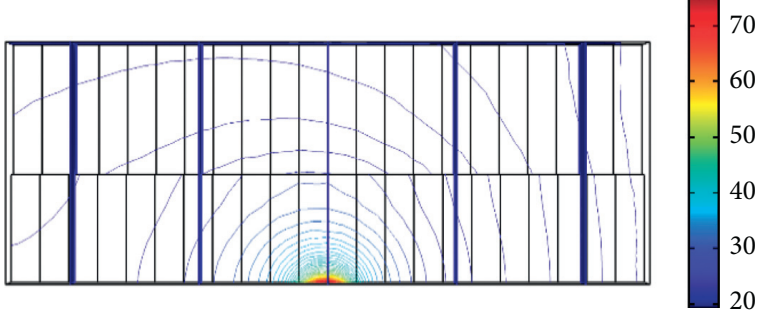

(b)

Figure 10: Flow field temperature distribution $\left({ }^{\circ} \mathrm{C}\right)$. (a) Axonometric drawing. (b) Top view.

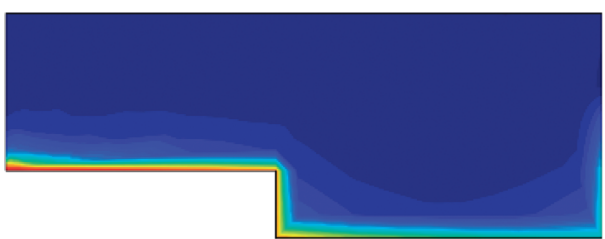

(a)

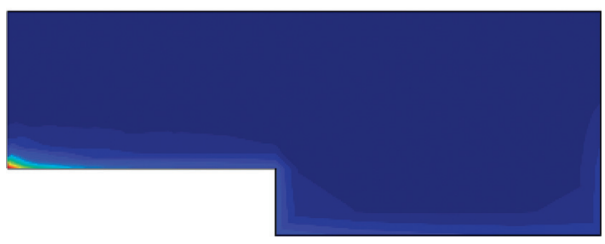

(c)

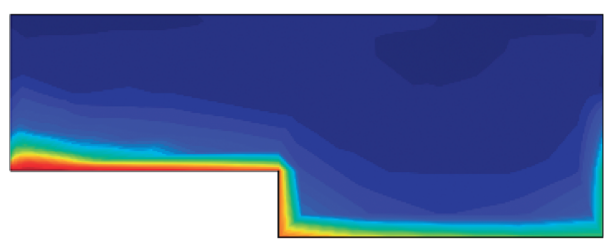

(e)
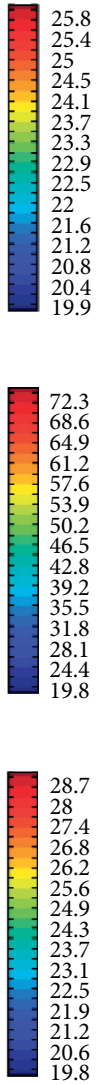

19.8

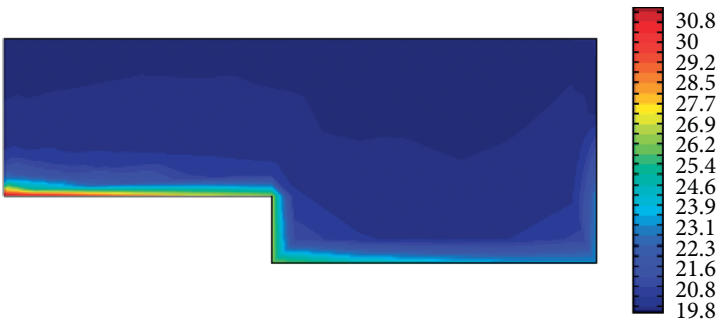

(b)

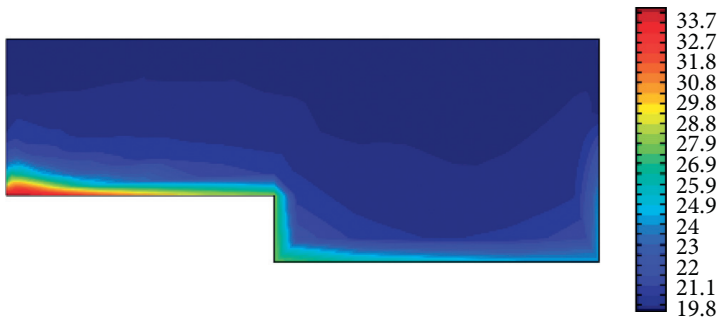

(d)

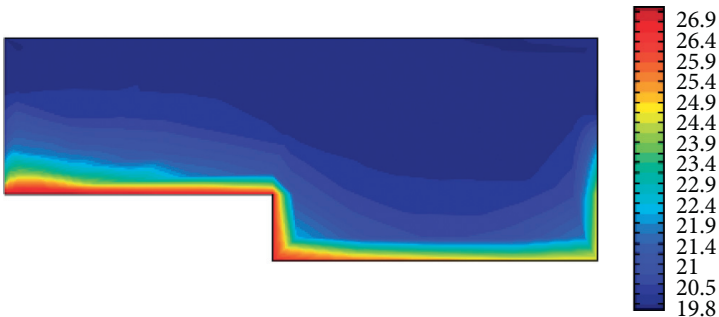

(f)

Figure 11: Sectional temperature distribution in the flow field at different times $\left({ }^{\circ} \mathrm{C}\right)$ : (a) $15 \mathrm{~s}$. (b) $20 \mathrm{~s}$. (c) $25 \mathrm{~s}$. (d) $30 \mathrm{~s}$. (e) $35 \mathrm{~s}$. (f) $40 \mathrm{~s}$.

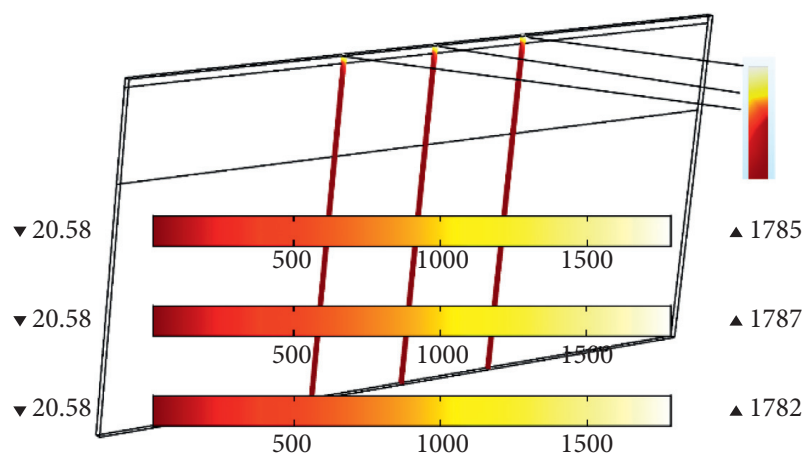

Figure 12: Three-section temperature distribution of the test piece $\left({ }^{\circ} \mathrm{C}\right)$. shown in Figure 13. From the comparison of the three cooling curves, it is found that the maximum temperature at different times of the three points decreases about $12^{\circ} \mathrm{C}$ compared with the natural cooling, and the temperature of each node decreases slightly during the cooling stage. By refining the calculation time step to $0.01 \mathrm{~s}$, the comparative data show that the cooling time of the three curves is shortened by $0.11 \mathrm{~s}, 0.09 \mathrm{~s}$, and $0.09 \mathrm{~s}$, respectively, and the average shortening time is $0.097 \mathrm{~s}$, and it accounts for about $3.6 \%$ of the total cooling time.

3.6.2. Comparison of Cooling Effects of Different Argon Flow Rates. Selected flow rates of $1 \mathrm{~m} / \mathrm{s}, 2 \mathrm{~m} / \mathrm{s}, 4 \mathrm{~m} / \mathrm{s}$, and $7 \mathrm{~m} / \mathrm{s}$ to 


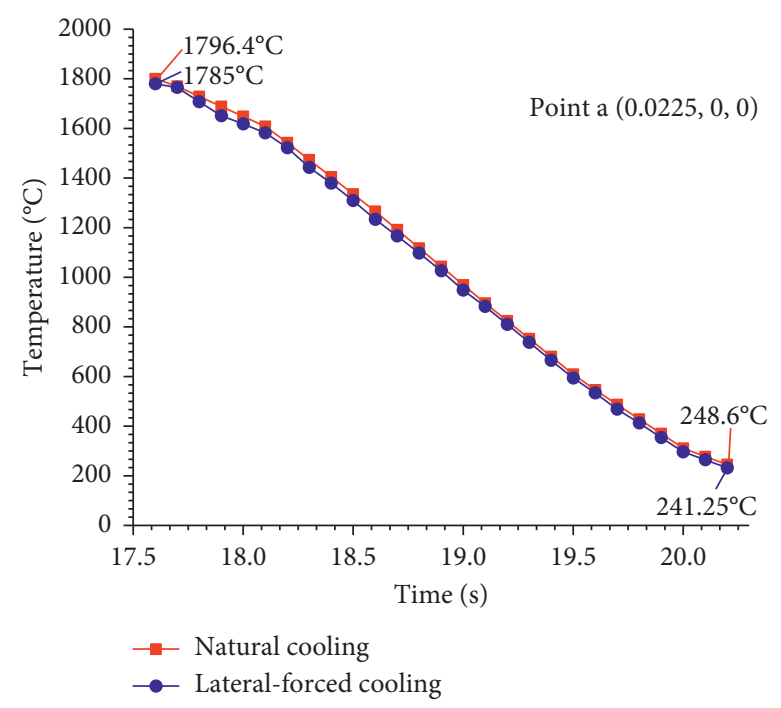

(a)

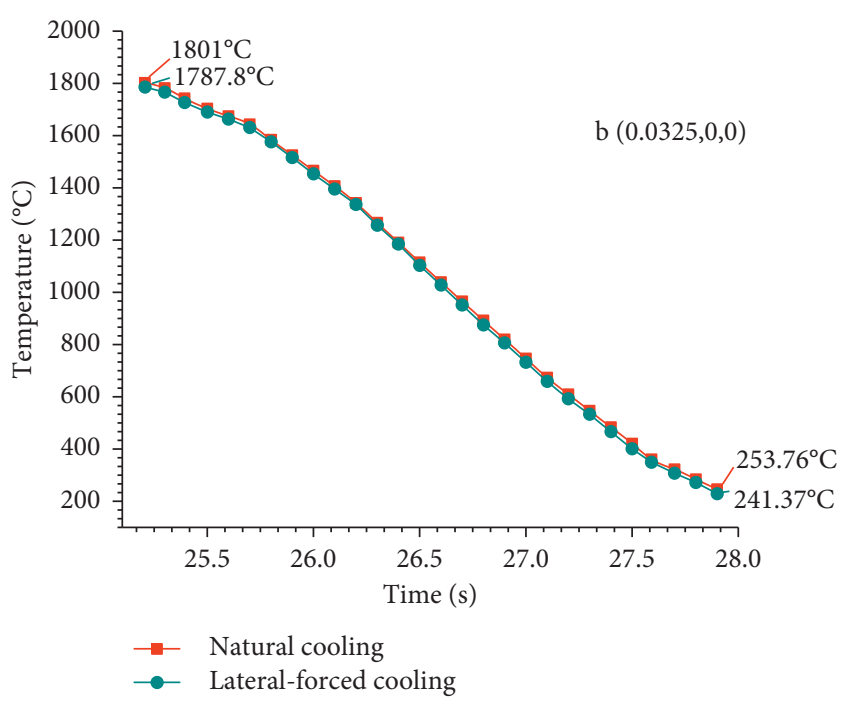

(b)

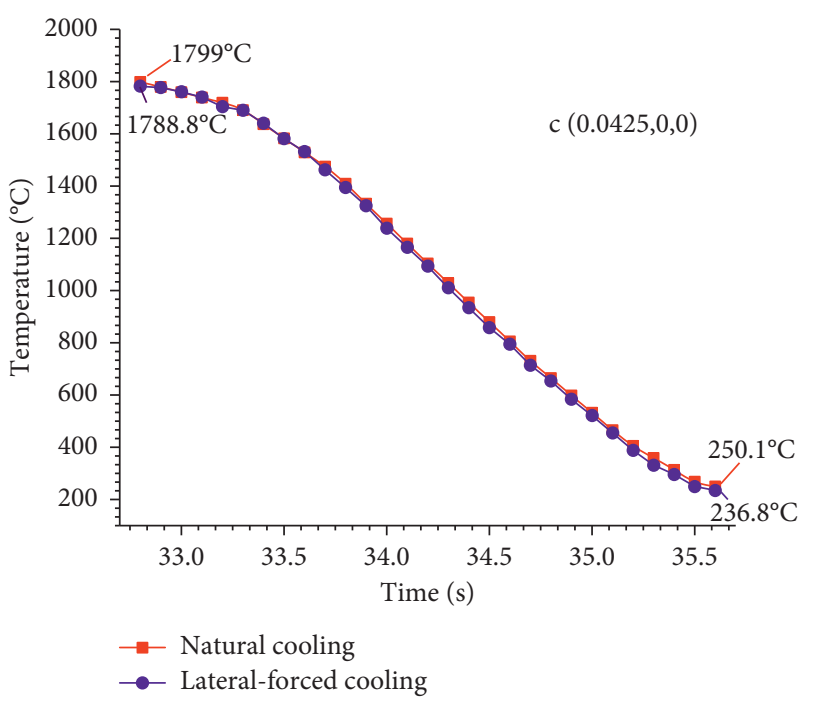

(c)

Figure 13: Feature points cooling curve comparison: (a) Point $a$, (b) Point $b$, and (c) Point $c$.

compare the cooling time of point $b$. The results show that the cooling effect is different at different flow rates, and the trend is the same. The comparison of cooling time for different argon flow rates are represented by bar graphs, as shown in Figure 14. The horizontal axis is the different argon flow rate, and the vertical axis is the cooling time.

It can be seen from Figure 14 that the cooling effect by lateral forced convection is better than nature cooling, but the overall effect is not excellent. When the wind speed is gradually increased from $1 \mathrm{~m} / \mathrm{s}$, the cooling effect is slowly enhanced. However, when the wind speed is continuously increased, the cooling time hardly changes and is in small fluctuation. Considering that when the wind speed is high, the heat transfer efficiency in the fluid will be accelerated, but at the same time, the heat exchange between argon and fixture will be insufficient. This weakens the enrichment effect of the particles on the upper surface of the fixture so that sufficient heat conduction cannot be performed inside the fluid. When the flow rate is small, although the heat exchange process is sufficient, the conduction capacity of the argon heat exchange amount per unit time is lower.

\section{Vertical Jet Impact Cooling Method}

4.1. Vertical Jet Impact Simplified Model of "Blade-Fixture". According to the flow rule of argon impact "blade-fixture," the flow field diagram is drawn, as shown in Figure 15.

Because of the complex flow characteristics of the impinging jet, there is no accurate theoretical formula for the distribution of convective heat transfer coefficient. The method of calculating average heat transfer coefficient first and then average convective heat flux density through the Newton cooling formula is adopted: 


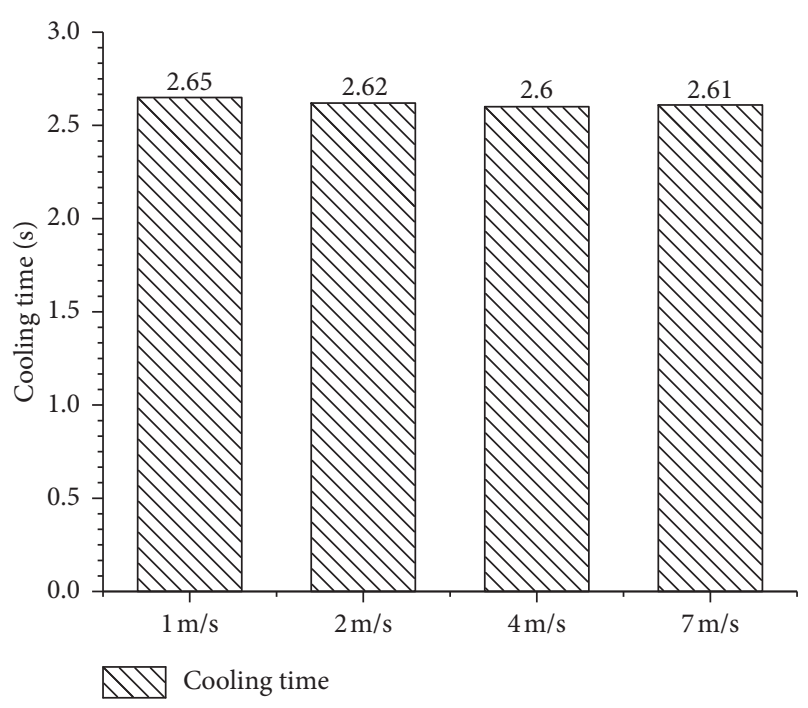

FIGURE 14: Comparison of cooling time for different argon flow rates.

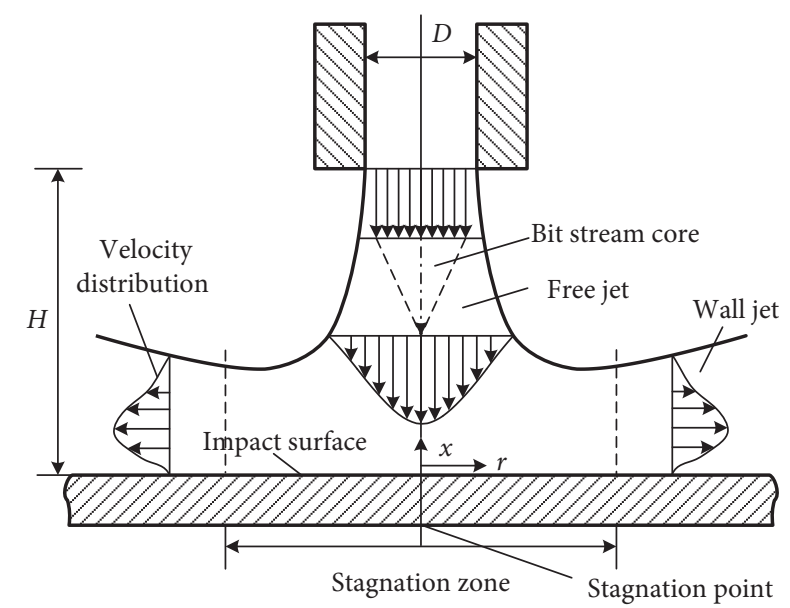

Figure 15: Schematic diagram of turbulent impinging flow field.

$$
\begin{aligned}
\bar{h} & =\frac{\overline{\mathrm{Nu}} \cdot \lambda}{d}, \\
\frac{\overline{\mathrm{Nu}}}{\operatorname{Pr}^{0.42}} & =G\left(\frac{r}{d}, \frac{H}{d}\right) \cdot F(\mathrm{Re}), \\
G\left(\frac{r}{d}, \frac{\mathrm{H}}{d}\right) & =\frac{\mathrm{d}}{r} \cdot \frac{1-1.1(\mathrm{~d} / r)}{1+0.1[(H / d)-6](d / r)}, \\
F(\mathrm{Re}) & =2\left[\operatorname{Re}\left(1+\frac{\mathrm{Re}}{200}\right)^{0.55}\right]^{0.5}, \\
\bar{q} & =\bar{h} \cdot \Delta t,
\end{aligned}
$$

where $r$ is the cooling radius and $d$ is the nozzle diameter.

However, for the fixture structure of MPAW automatic welding machine, the average convective heat flux density cannot accurately represent the actual impact characteristics. In this work, the convective heat flux distribution curve of argon impact cooling on the wall is obtained by establishing a simplified model simulation, then the simulation results are applied to the welding model in the form of boundary conditions, and then compared with the results of the average heat transfer coefficient method. According to welding process, the upper surface of the blade is only $0.8 \mathrm{~mm}$ higher than the fixture surface and the blade and the fixture can be regarded as the same plane. The simplified model of the impact "blade-fixture" is shown in Figure 16, which is to analyze the cooling effect of different impact parameters and obtain the best impact parameters. Many scholars have studied the choice of the turbulence model [20-22]. In turbulent impinging flow field, high wall velocity and fluid fluctuation can cause fully developed turbulence and the $k-\varepsilon$ model is suitable for calculation [23]. The model $k-\varepsilon$ is a twoequation model developed based on the $k$ one-equation model, which represents the turbulent kinetic energy. It has a wide range of applicability. Therefore, the $k-\varepsilon$ turbulence model was chosen and the jets studied were all submerged jets.

As shown in Figure 16, the argon nozzle is located above the center of the impact zone. The length of the nozzle is $h_{1}$, the diameter is $d_{0}$, the middle chamber is the fluid flow space, the impact height is $H$, the diameter is $D$, the bottom disc is the solid impact wall, and the thickness is $h_{2}$. The simulation uses velocity to flow into the inlet and pressure outlet. The inlet velocity is set to $V$. Argon flows out from the side and upper surface of the cavity after injecting the nozzle into the solid wall. The initial inlet temperature of argon is $T_{1}$ and the wall temperature is $T_{2}$. The initial parameters of the model are shown in Table 3.

4.2. Influence of Different Model Parameters on Impact Cooling Characteristics. The steady-state solver and the direct solver PARDISO are used to solve the model. The coupling connection between the thermal field and the flow field was set, and the boundary layer meshing model was used to obtain the simulation result through postprocessing. The solid region was taken as the research object. Figure 17 shows the overall velocity streamline distribution in the process of argon vertical impact. The streamline shows the direction and size of velocity. It can be seen that the diameter of cross section of argon before reaching the wall increases slightly, the velocity direction bends at 90 degrees in front of the wall, the velocity decreases rapidly to zero, and then rapidly converts into wall-attached flow.

Figure 18 shows the velocity distribution of the section in the interception model. The triangle of the potential flow core at the front end of the nozzle can be clearly seen. The velocity of this region is the largest, and the turbulent flow reaches $45 \mathrm{~m} / \mathrm{s}$, and then enters the main stage, and the velocity decays greatly. The cross-sectional velocity distribution is approximately bell-shaped. When the stagnation point is reached, the velocity is reduced to zero, and the adhering flow velocity is only about $18 \mathrm{~m} / \mathrm{s}$.

The calculated wall-facing heat flux distribution and conductive heat flux distribution are shown in Figures 19 and 20. Convective heat flux characterizes the heat transfer 


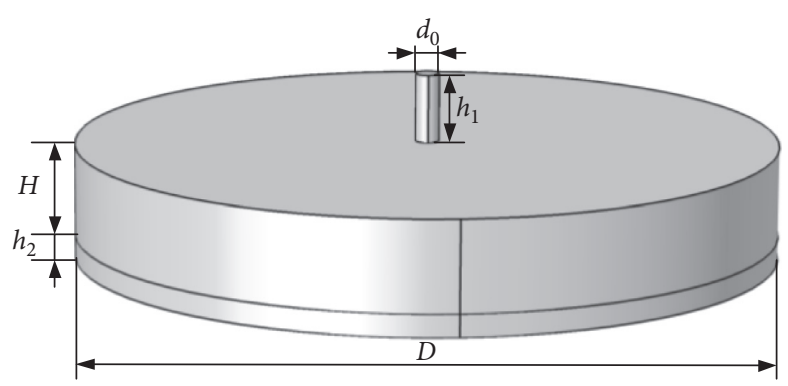

FIGURE 16: Simplified model of impact cooling.

TABLE 3: Initial parameters of the model.

\begin{tabular}{lcccccccc}
\hline Parameter & $d_{0}$ & $h_{1}$ & $H$ & $h_{2}$ & $D$ & $T_{1}$ & $T_{2}$ & $V$ \\
\hline Value & $2 \mathrm{~mm}$ & $6 \mathrm{~mm}$ & $8 \mathrm{~mm}$ & $2 \mathrm{~mm}$ & $60 \mathrm{~mm}$ & $20^{\circ} \mathrm{C}$ & $650^{\circ} \mathrm{C}$ & $35 \mathrm{~m} / \mathrm{s}$ \\
\hline
\end{tabular}

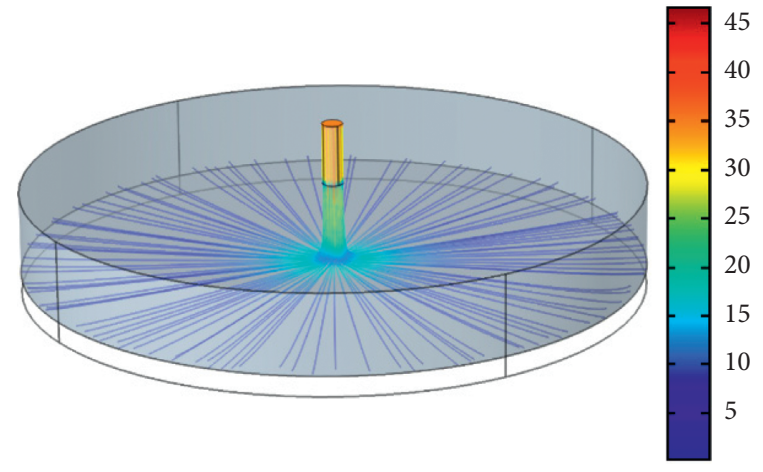

FIGURE 17: Overall velocity streamline distribution $(\mathrm{m} / \mathrm{s})$.

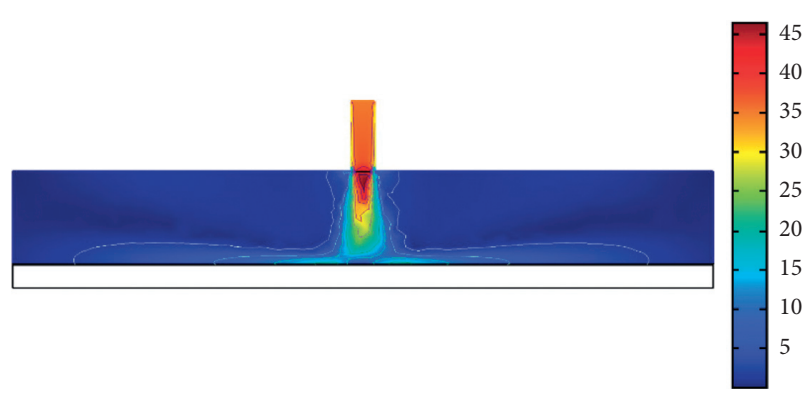

Figure 18: Velocity distribution of the medium section $(\mathrm{m} / \mathrm{s})$.

per unit area caused by convective heat transfer. It is circular in the whole. The middle heat flux is large and the edge is small. Since the velocity of the impact zone is the largest, the convective heat flux is also the largest, but it is small at the stagnation point because although the wall pressure is large, the radial velocity is small and the convective heat flux is small. Similarly, conductive heat flux represents the heat transfer per unit area caused by heat conduction. The impact force at the stagnation point is the greatest and the boundary layer is the thinnest. Therefore, the heat dissipation at the stagnation point is mainly in the form of heat conduction. Later, the adherent boundary layer becomes thicker and the heat conduction is weakened due to the thermal resistance formed by the boundary layer. The main way of heat dissipation is convective heat transfer.

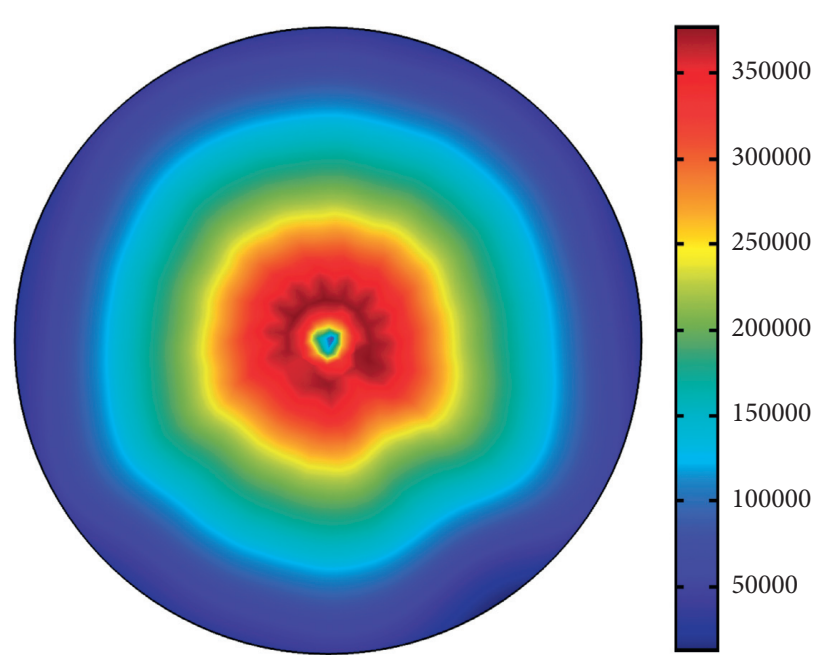

FIgUre 19: Heat flux distribution of wall convection $\left(\mathrm{W} / \mathrm{m}^{2}\right)$.

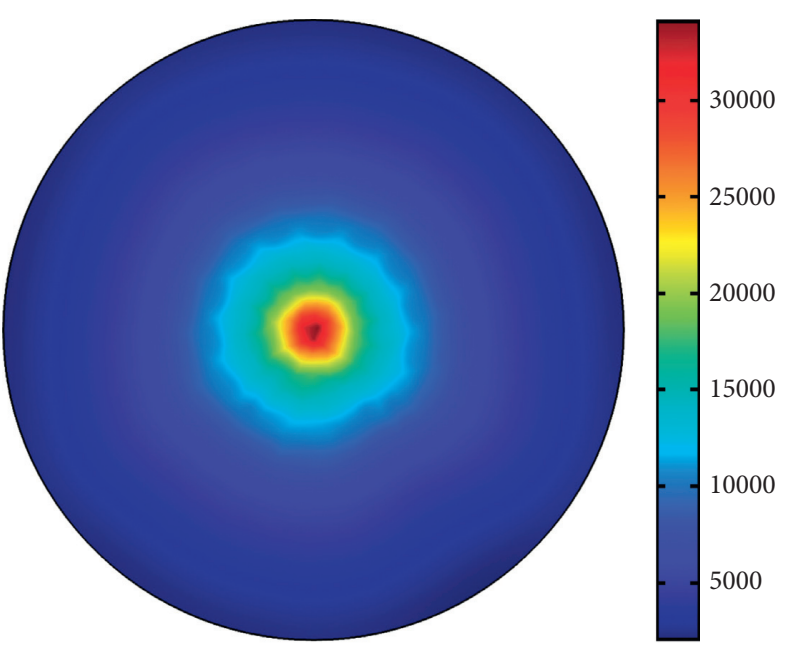

Figure 20: Distribution of wall conduction heat flux $\left(\mathrm{W} / \mathrm{m}^{2}\right)$.

Because the difference between conductive heat flux and convective heat flux in the stagnation point region is an order of magnitude, it can be neglected. And if the center of the heat sink is too close to the center of the heat source, it 
will affect the shape of the molten pool. Therefore, this work only considers the maximum convective heat flux at the edge of the impact zone. Because the heat sink moves at the same speed with the heat source, the cooling argon is rapidly pumped away when it reaches the wall, and the wall-attached jet zone cannot fully develop. Moreover, the welding arc energy is concentrated and protected by argon compression. So, the influence of the adherent jet zone on the molten pool is not considered.

The key parameters affecting the heat transfer performance of the argon impact cooling system are the impact height, nozzle diameter, and inlet flow rate.

\subsubsection{Effect of Different Impact Heights on Cooling Performance.} Because the change in diameter will cause the change of the overall size of the flow field, this study does not perform a separate fixed value analysis on the impact height and the nozzle straight, but combines the two parameters together for the overall analysis. The fixed nozzle diameter is $d=2 \mathrm{~mm}$ and the impact height is $2 d, 4 d$, and $8 d$ to compare flow characteristics at different heights.

The wall pressure distribution at different impact heights is shown in Figure 21. The maximum pressure is concentrated near the stagnation point. The smaller the impact height, the maximum the wall pressure and the faster the pressure decay.

The wall velocity distribution at different impact heights is shown in Figure 22. The velocity near the stagnation point is small, the impact zone reaches the maximum velocity and then decays rapidly. When the impact height is $2 d$, the attenuation speed is the fastest and the attenuation is the slowest at $8 d$. Combined with the two figures, it can be found that as the impact distance decreases, the pressure first decreases to zero and the velocity first reaches the maximum value. The pressure wave energy is all converted into the adherent flow energy.

The heat flux distribution of wall surface convection at different impact heights is shown in Figure 23. The heat flux near the stagnation point is the smallest, and the heat flux in the impact zone is the largest. There is an optimal impact height of $4 d$, and the maximum convective heat flux is reached near the radial distance of $2 d$. The convective heat transfer effect will be reduced if the impact height is too small or too large. This is because when argon enters a stationary environment, the central velocity of flow is high and the pressure is low. The turbulent pulsation will absorb the stationary particles around it and form a turbulent mixing layer. Because of the transverse transfer of momentum, the axial velocity decreases, the jet cross section expands, and the flow rate increases along the path. When the impact height is too small, the cross section expands slightly, the entrainment effect is weak, and the flow rate along the path is small, so the heat transfer effect is poor. When the impact height is high, the entrainment effect is large, but the transverse velocity of the wall is too small to achieve good heat transfer effect. In summary, the best impact height is selected for $4 d$ for subsequent simulation analysis.

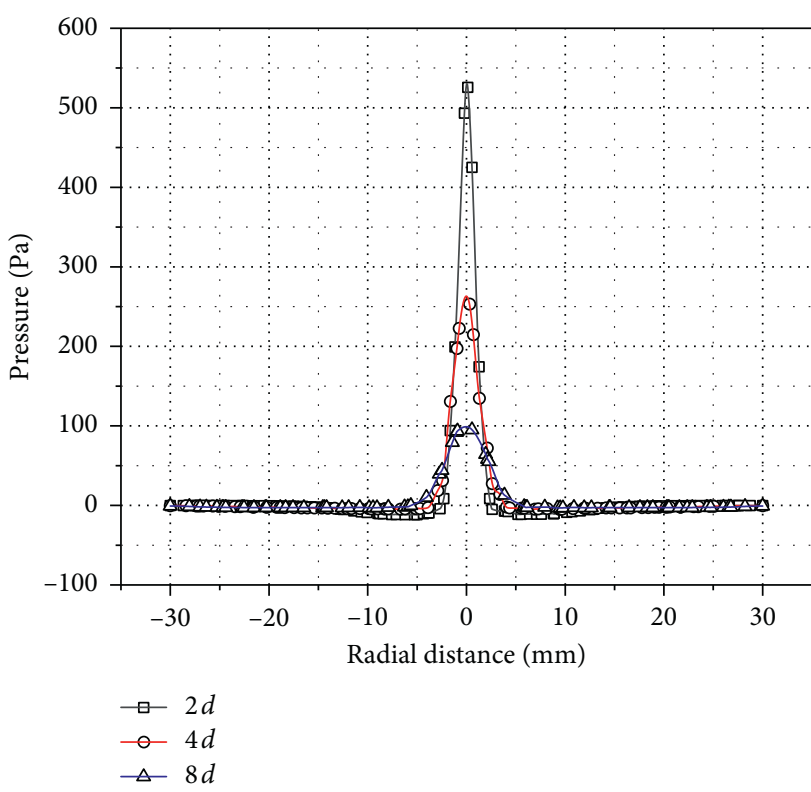

FIgURE 21: Wall pressure distribution at different impact heights.

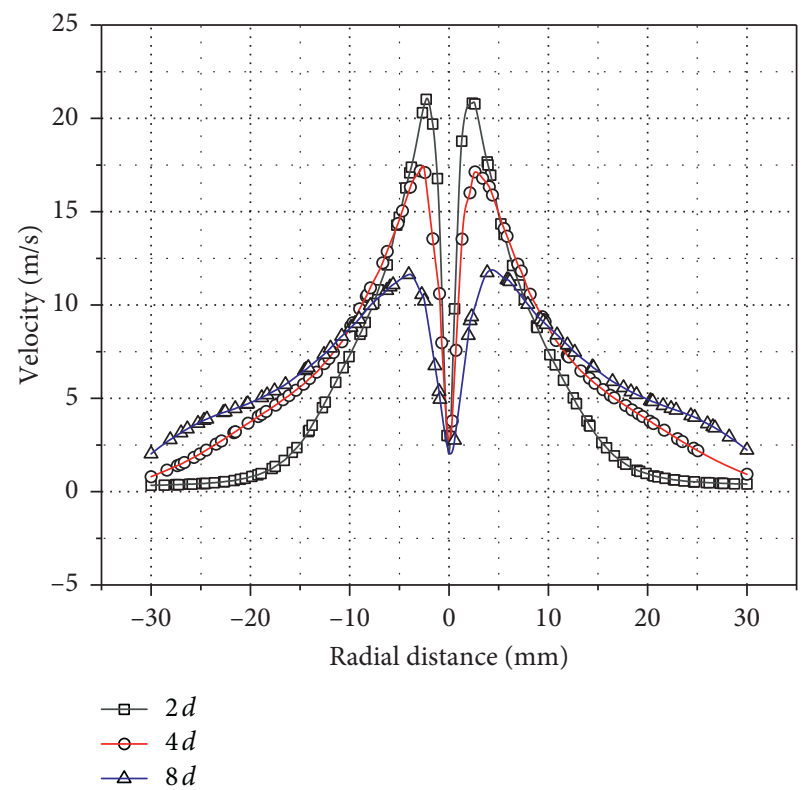

FIGURE 22: Wall velocity distribution at different impact heights.

4.2.2. Effect of Nozzle Diameter on Cooling Performance. The fixed impact height is $4 d$, the nozzle diameter is $1 \mathrm{~mm}$, $2 \mathrm{~mm}$, and $3 \mathrm{~mm}$, and the other parameters are initial values. The wall pressure distribution of different nozzle diameters is shown in Figure 24. It can be seen that the maximum wall pressure increases with the diameter of the outlet. When the diameter is $1 \mathrm{~mm}$, the difference is larger than the diameter of $2 \mathrm{~mm}$. This is because at the same flow rate, the larger the outlet diameter, the larger the fluid flow rate, the greater the kinetic energy, and the greater the pressure after impacting the wall surface.

The wall velocity distribution of different nozzle diameters is shown in Figure 25. The velocity of the fluid at 


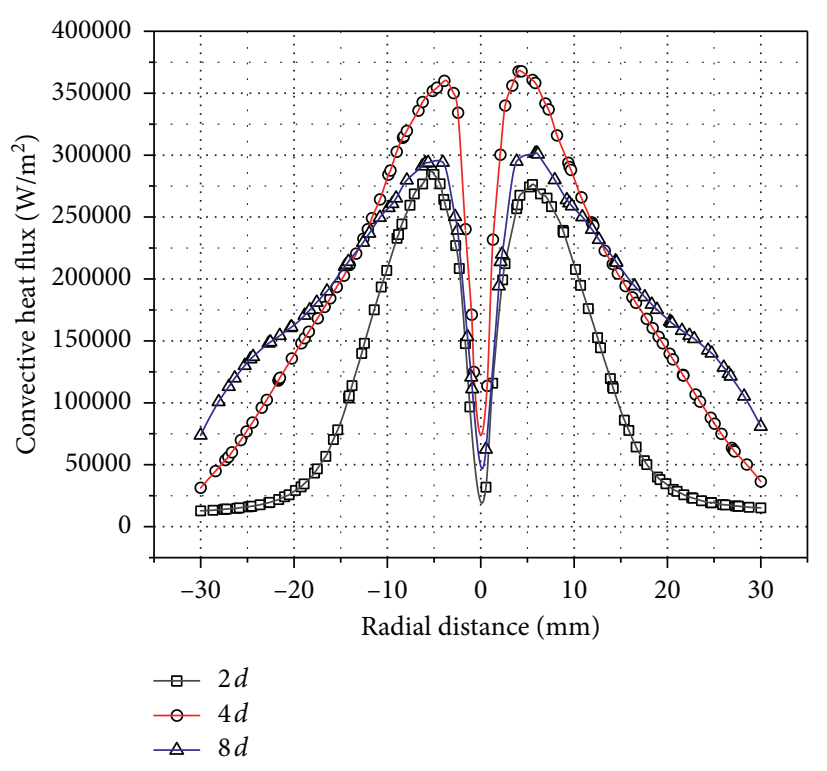

FIgUre 23: Heat flux distribution of wall surface convection at different impact heights.

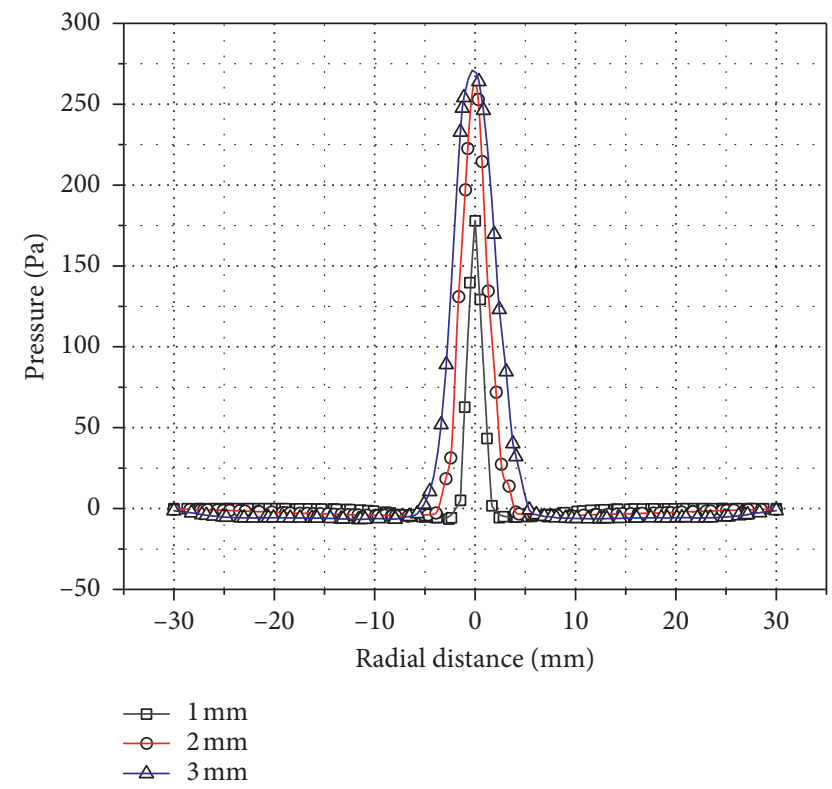

Figure 24: Wall pressure distribution of different nozzle diameters.

different diameters is not much different at the stagnation point. The pressure wave energy can be quickly converted into kinetic energy after impacting the wall surface. The maximum adhesion velocity is reached at about $2 d$ from the center. The maximum velocity increases with increasing diameter, but the increase step gradually decreases. Because the flow rate increases, the proportion of momentum loss caused by fluid impact on the wall decreases relatively, and the speed is relatively increased.

The heat flux distribution of wall convection with different nozzle diameters is shown in Figure 26. The maximum heat flux of $1 \mathrm{~mm}$ diameter and $2 \mathrm{~mm}$ diameter is greater than $3 \mathrm{~mm}$ diameter, but the heat flux decays slowly at $3 \mathrm{~mm}$

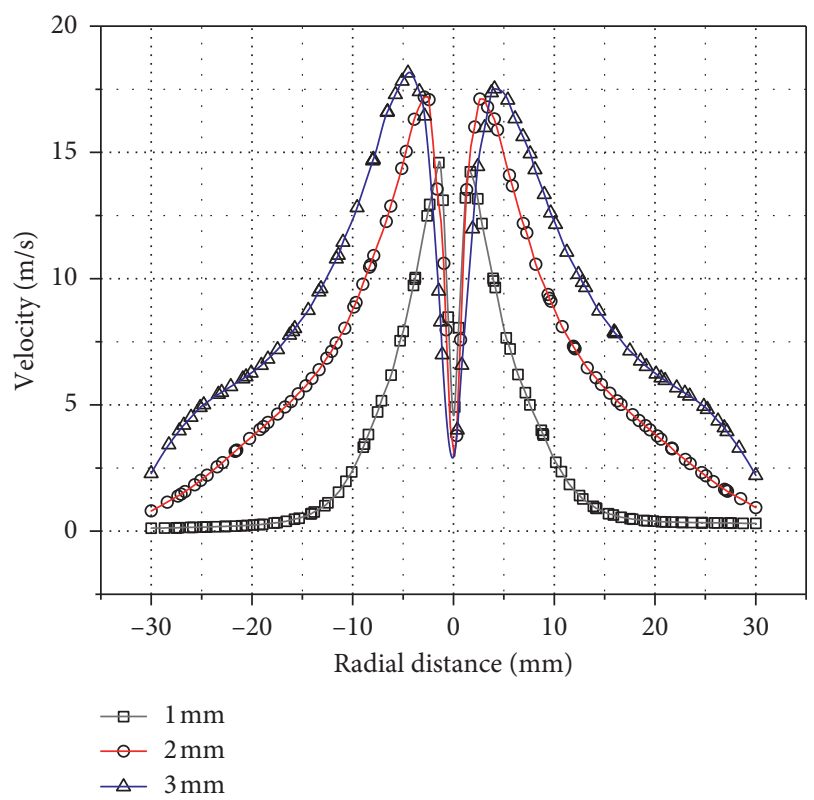

FIGURE 25: Wall velocity distribution of different nozzle diameters.

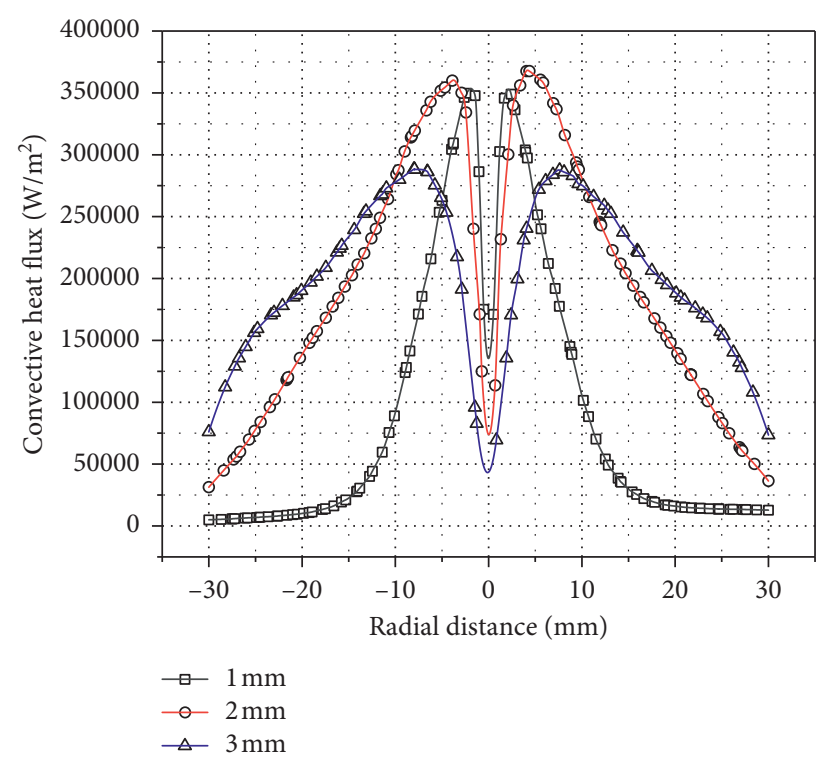

Figure 26: Heat flux distribution of wall convection with different nozzle diameters.

diameter. Considering the increase in outlet diameter, the center fluid is concentrated and the outer ring fluid restricts the central fluid momentum to transmit laterally, so the convective heat transfer effect is weakened, but the effective area of convective heat transfer increases.

The cloud map of wall surface heat flux distribution under different nozzle diameters is shown in Figure 27. It can be seen from the three distribution clouds that the effective area of convective heat transfer increases with the increase of diameter. When the nozzle diameter is $3 \mathrm{~mm}$, although the convective heat transfer strength in the impact zone is weakened, the heat exchange area is increased. 


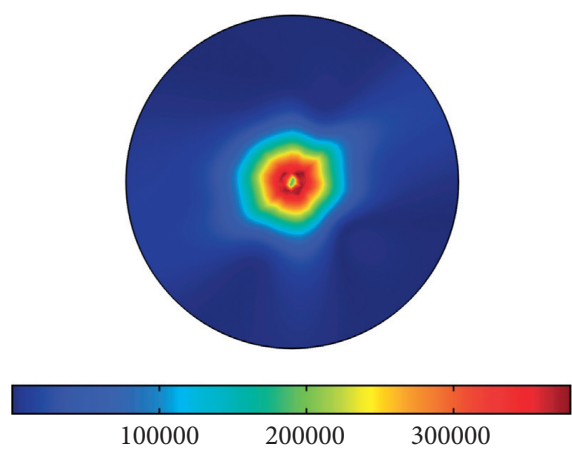

(a)
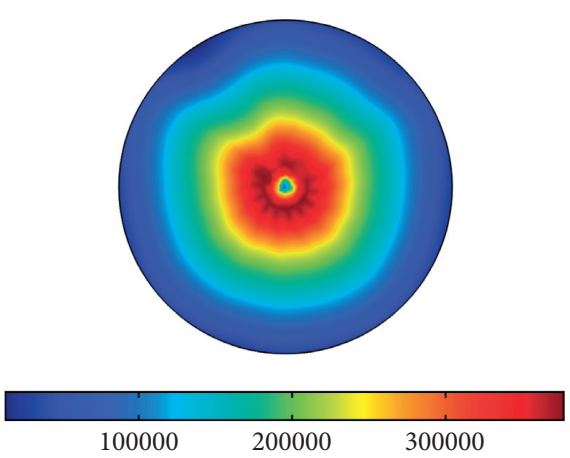

(b)

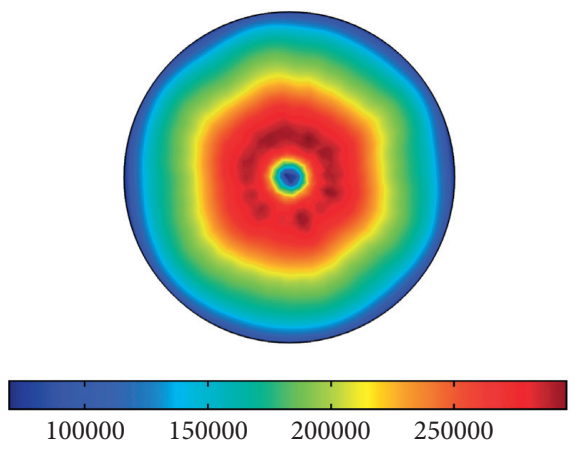

(c)

Figure 27: Cloud map of wall surface heat flux distribution under different nozzle diameter conditions: (a) $1 \mathrm{~mm}$, (b) $2 \mathrm{~mm}$, and (c) $3 \mathrm{~mm}$.

In order to systematically study the influence of the nozzle diameter on the flow heat flux of the wall, two sets of $1.5 \mathrm{~mm}$ and $2.5 \mathrm{~mm}$ diameter simulation experiments were added to compare the average convective heat flux of the impact wall of the five groups of diameters. The curves are shown in Figure 28. As the nozzle diameter increases, more fluid will participate in the heat exchange, resulting in an increase in the average convective heat flux across the wall. The theoretical results of the average convective heat flux calculated by the comparison formulas (22) to (26) have the same overall trend. When the nozzle diameter is $2 \mathrm{~mm}$, the difference between the two curves is the smallest. Therefore, the nozzle diameter was taken to be $2 \mathrm{~mm}$ for the subsequent calculations.

4.2.3. Influence of Inlet Flow Rate on Cooling Performance. Three different rates set of argon inlet flow were taken at $20 \mathrm{~m} / \mathrm{s}, 35 \mathrm{~m} / \mathrm{s}$, and $50 \mathrm{~m} / \mathrm{s}$. The corresponding Re is 3418 , 5986 , and 8525 . The convective heat flux of the impact wall is analyzed under different inlet flow rates with the same model parameters. The results are shown in Figure 29.

It can be seen that the convective heat flux increases with the increase of the inlet flow velocity and the enhanced heat exchange capacity becomes stronger. The inlet flow rate was chosen to be $35 \mathrm{~m} / \mathrm{s}$ as the inlet flow rate for subsequent simulations.

4.2.4. Moving Heat Sink Model. The schematic diagram of heat sink and heat source on the upper surface of the test

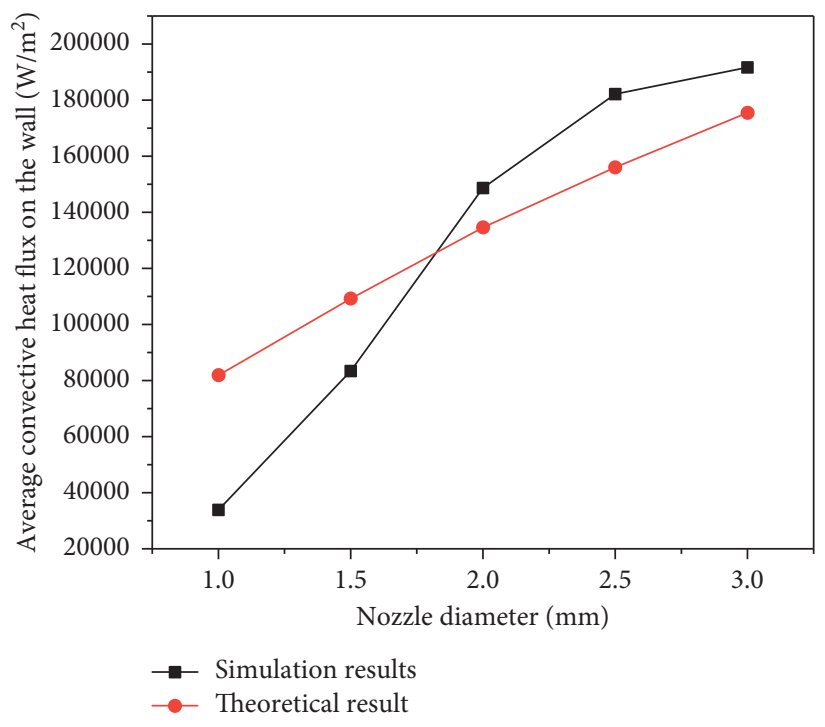

FIgURE 28: Average convective heat flux on the wall of different nozzle diameters.

piece are shown in Figure 30. The simulation results show that under the given parameters, the function of surface heat flux distribution of argon vertical impact cooling is $Q(r)$, which characterizes the heat away from the argon convection heat transfer per unit area, and $r$ is the radial distance from the stagnation point of the impact zone. The results show that the convective heat flux reaches the maximum at the radial distance of $2 d$, so the $r=2 d$ is taken as the heat sink radius. For any point $(x, y)$ on the fixture and the surface of 


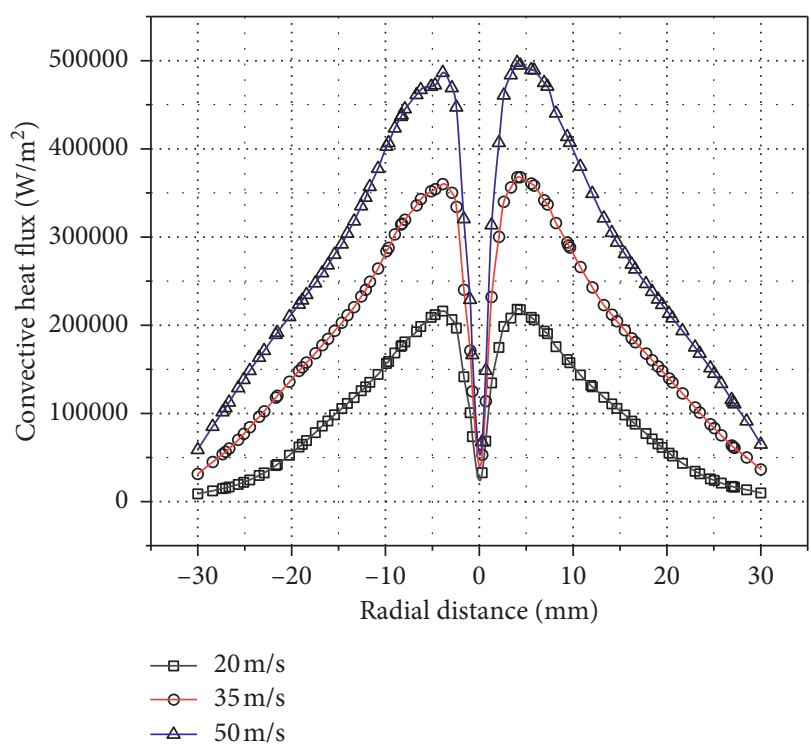

FIGURE 29: Distribution of surface convective heat flux at different inlet velocities.

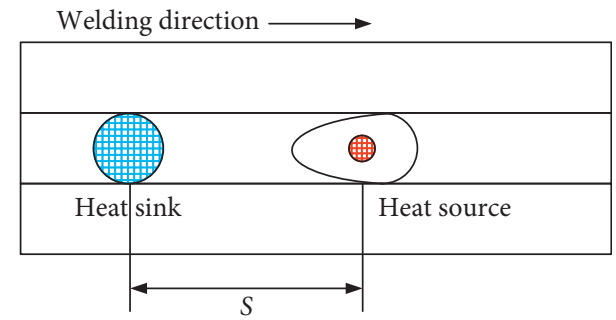

Figure 30: Schematic diagram of heat sink and heat source.

the blade, the convective heat flux can be expressed as follows:

$$
Q(r)=Q\left(\sqrt{x^{2}+y^{2}}\right) .
$$

The heat sink center is located at the rear $S$ of the heat source center, and the moving speed is $v$. The moving heat sink model is expressed as follows:

$$
q(r)=-Q\left(\sqrt{(x+S-v t)^{2}+y^{2}}\right), \quad r \leq 2 d .
$$

Based on the abovementioned calculations, the jet impact cooling effect can be further calculated by adding the heat sink to the model boundary conditions in the form of heat flux.

\subsubsection{Cooling Effect Analysis of Vertical Jet Impact Cooling.} The distance $S$ between the heat sink and the heat source has a great influence on the cooling effect after welding. If the distance is too small, the argon will affect the shape of the molten pool. If the distance is too large, due to the high concentration of the welding arc and the low thermal conductivity of the alloy, the cooling effect is not obvious. It is necessary to calculate the appropriate distance between the heat sink and heat source first.
In order to analyze the influence of the distance $S$ quantitatively, it is important to determine the heat sink strength. From the previous simulation, the better model parameters are the impact height of $4 d$, the nozzle diameter of $2 \mathrm{~mm}$, and the inlet flow rate of $35 \mathrm{~m} / \mathrm{s}$. The normal temperature argon is used as the cooling medium. The melting point of $\mathrm{TC} 4$ alloy is about $1650^{\circ} \mathrm{C}$, that is, the upper surface of the test piece is $1650^{\circ} \mathrm{C}$, which is the molten pool solid-liquid line. It should be noted that the heat sink area could not cover the molten pool part.

Ignoring the influence of the wall-attached jet zone on the molten pool, the simulation experiments were carried out with 3 sets of different $S$ of $7 \mathrm{~mm}, 8 \mathrm{~mm}$, and $9 \mathrm{~mm}$. The center point of the test piece was taken as the research object, and the thermal cycle curves comparing with natural cooling welding conditions under three value of $S$ are shown in Figure 31. The results are a comparison of $22 \sim 28 \mathrm{~s}$ thermal cycle curves intercepted. The black dotted line is the thermal cycle curve under ordinary welding. The right one is a local enlargement of the cooling stage.

It can be seen that the impact heat transfer at different intervals is obvious faster in the cooling stage than in natural cooling conditions. It also does not affect the heating stage and the maximum temperature of the welding process and has no effect on the solid-liquid line. When $S=7 \mathrm{~mm}$, the cooling speed is the fastest, and it is the slowest when $S=9 \mathrm{~mm}$. The results indicated that the smaller the $S$, the larger the cooling rate. However, if $S$ is too small, it will affect the shape of the molten pool, so the appropriate distance of $S$ should be selected during welding.

According to the calculation results, when $S=7 \mathrm{~mm}$, the cooling time is $2.4 \mathrm{~s}$, which is $0.29 \mathrm{~s}$ shorter than the natural cooling welding. The shortened time accounts for $12.5 \%$ of the total cooling time.

For further comparing with the isothermal line distribution of the test piece under the condition of natural cooling and the $7 \mathrm{~mm}$ vertical impact cooling, the intercepting of the temperature range is set as $20^{\circ} \mathrm{C}-1800^{\circ} \mathrm{C}$, and the step length is $20^{\circ} \mathrm{C}$. The isotherm comparison chart is shown in Figure 32.

As shown in Figure 32, it is found that the vertical impact cooling has no effect on the maximum temperature of the molten pool. The heat sink behind the welding heat source reduces the isotherm distribution area of the heat affected zone, makes the rear denser, and has less influence on the front. At the same time, a tail-like room temperature area is formed behind the welding heat source, which shows that the argon vertical impact not only effectively takes the heat from the upper surface of the alloy but also speeds up the inside of it. The heat affected zone was reduced by heat transfer efficiency. Thus, the overall cooling rate is effectively increased.

Removing the alloy, Figure 33 is a comparison of fixture temperature distribution under natural cooling with that under argon vertical impact cooling. It is also found that vertical impact cooling can shrink and densify the isotherm area and generate local heat sink in the rear part, which accelerates the heat conduction in the fixture. 


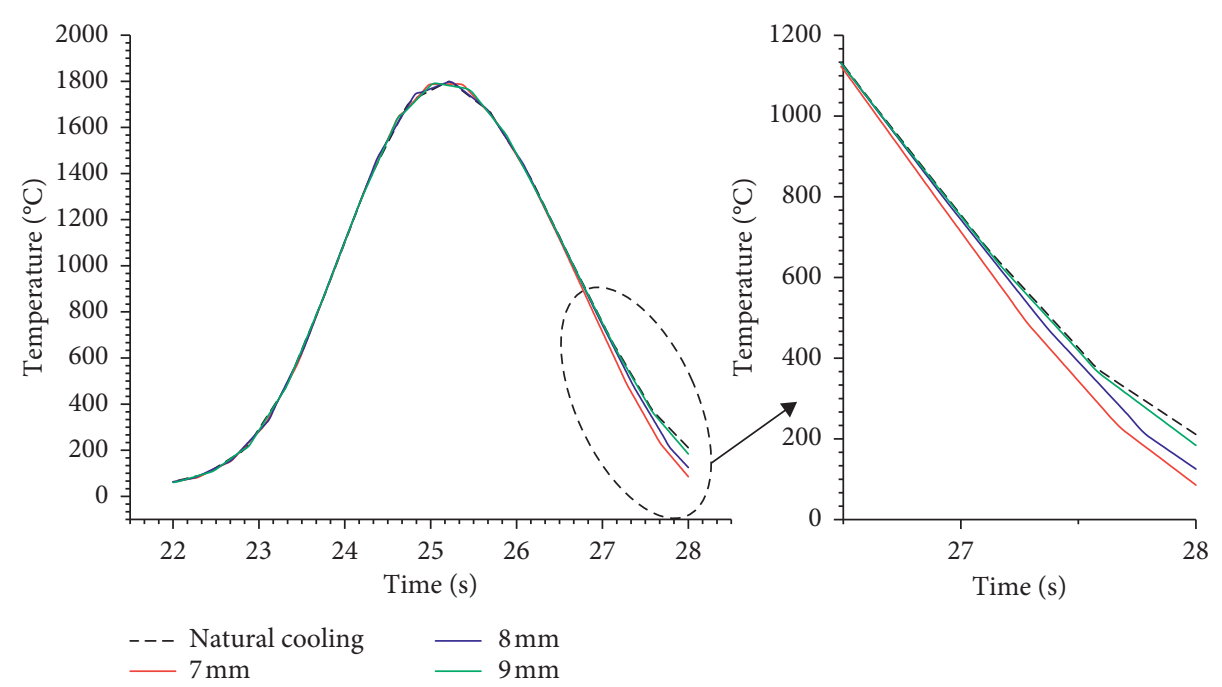

FIgURE 31: Thermal cycle curves comparison of different distance impact cooling and natural cooling.

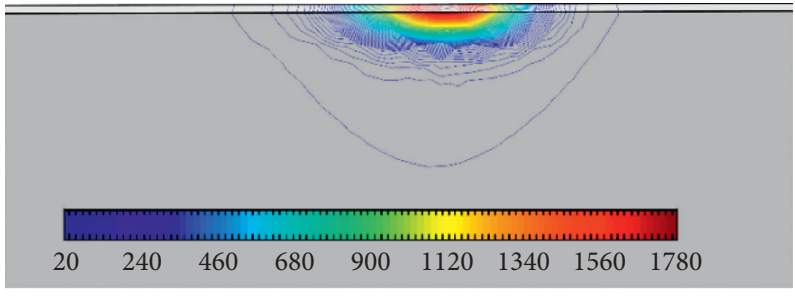

(a)

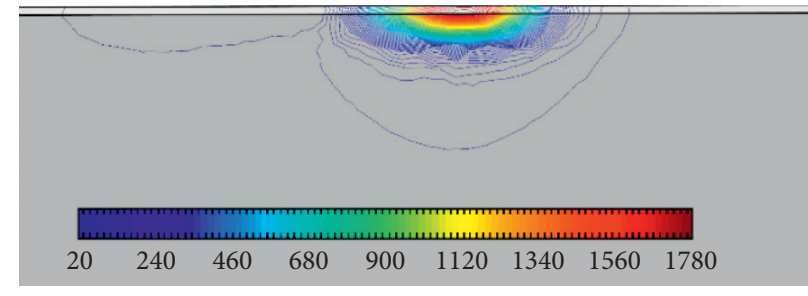

(b)

FIgURE 32: Isotherm comparison $\left({ }^{\circ} \mathrm{C}\right)$ : (a) natural cooling; (b) vertical impact cooling.

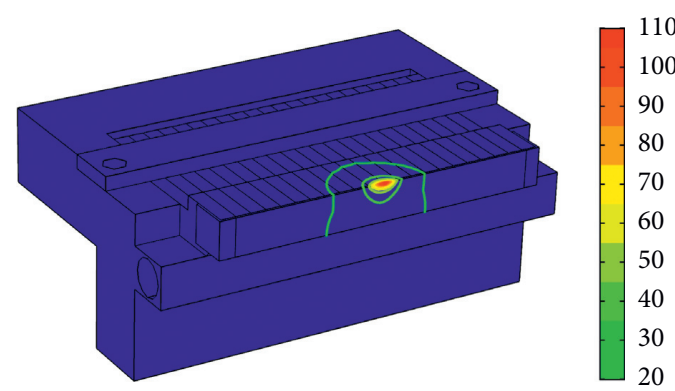

(a)

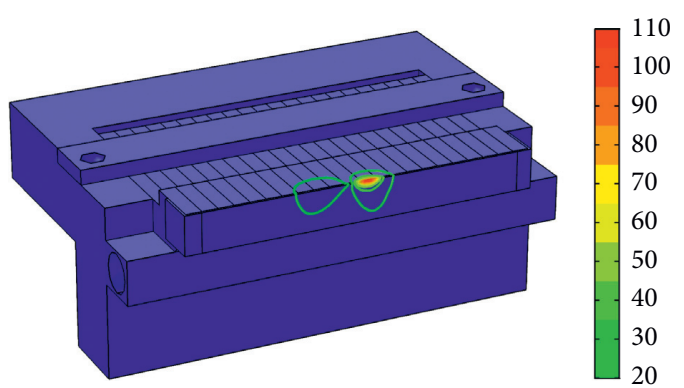

(b)

FIgURE 33: Fixture temperature distribution comparison $\left({ }^{\circ} \mathrm{C}\right)$ : (a) natural cooling; (b) vertical impact cooling.

\section{Experiment}

The welding equipment is CAUC-BW100 MPAW automatic welding machine and the argon vertical nozzle was improved according to the simulation results. The chemical composition of the test piece and titanium alloy welding wires used in the experiment are shown in Table 4, in which the diameter of welding wires is $0.76 \mathrm{~mm}$. Titanium alloy easily absorbs impurities in the air when it is cooled for a long time, which will cause the color change of the weld to be obvious. According to this feature, two weld beads are deposited on the test piece, and the welding effect after jet impact cooling can be compared.
TABle 4: The chemical composition of the test piece and wire (wt.\%).

\begin{tabular}{lcccccccc}
\hline & $\mathrm{Al}$ & $\mathrm{V}$ & $\mathrm{Fe}$ & $\mathrm{C}$ & $\mathrm{N}$ & $\mathrm{H}$ & $\mathrm{O}$ & $\mathrm{Ti}$ \\
\hline Test piece & 6.04 & 3.96 & 0.3 & 0.08 & 0.05 & 0.015 & 0.2 & Rest \\
Wire & 6.03 & 3.89 & 0.19 & 0.03 & 0.008 & 0.002 & 0.15 & Rest \\
\hline
\end{tabular}

The results are shown in Figure 34. For the first bead of surfacing, it was found that there was no significant difference in the color of the weld bead, indicating that during the first surfacing, due to the low-surfacing height, the original cooling and the natural convection of the fixture can meet the heat dissipation requirements. 


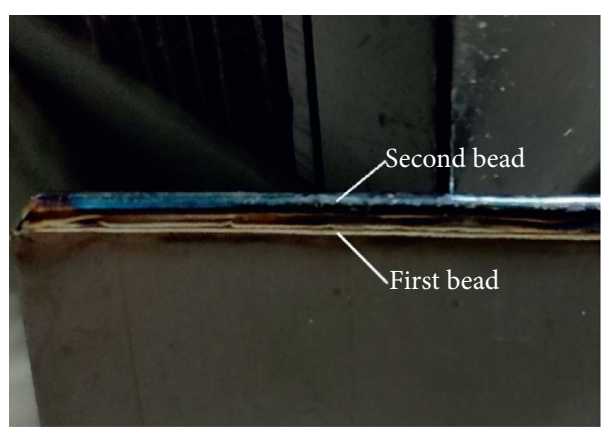

(a)

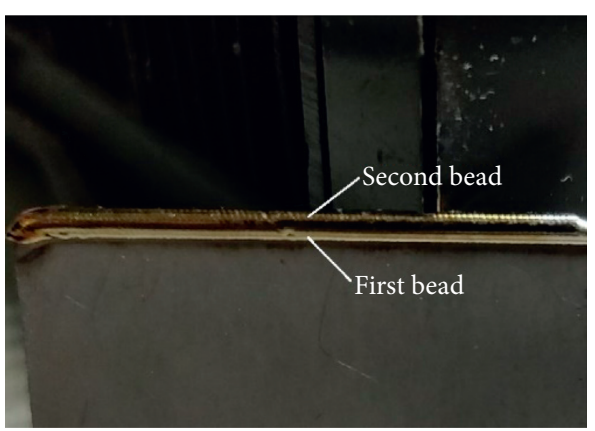

(b)

Figure 34: Comparison of welding result. (a) No vertical jet impact cooling method. (b) Vertical jet impact cooling method.

However, for the second surfacing bead, with the increase of the surfacing height, due to the poor thermal conductivity of the test piece itself, the heat transfer from the test piece to the fixture is weakened, so the heat carried away by the fixture is greatly reduced. Although the inert gas protection measures are used, the cooling time is long and the weld still sucks in some impurities. Showing an undesired blue color. The second weld bead with jet impact cooling has a significant improvement in color, indicating that jet impact cooling shortens the residence time of the weld above $250^{\circ} \mathrm{C}$, which has a good cooling effect and is of positive significance for the second surfacing.

There are some uncertain factors that influence results, which need to be further studied. The thickness of the first layer of the numerical mesh is the crucial parameter influencing the flow distribution in numerical analysis concerning impinging jets. For that reason, the optimal mesh generation is a problem worth further study in jet impact cooling. In addition, the uncertain factors such as room temperature, nozzle vertical angle, airflow disturbance to heat source, fixture assembly gap, and the effect of clamping force on heat transfer, may affect the experimental results. Moreover, the further work will design and improve the experimental device to verify different model parameters separately. We will continue to study the refinement and validation of model parameters.

\section{Conclusion}

(1) Through the heat transfer modeling of the bladefixture and the simulation calculation of the characteristic points of MPAW surfacing repair, the thermal cycle characteristics of the ultrathin blade surfacing process were analyzed in detail. Meanwhile, the heat transfer process in the key heat dissipation area and original cooling time were calculated.

(2) Through modeling and simulation calculations, the heat transfer rules of the two cooling methods were analyzed in detail and the cooling time was calculated. By comparing the cooling effect, it was found that both methods can improve the cooling effect and the vertical jet impact cooling effect is more obvious.
(3) For the vertical jet impact cooling method, the pressure, flow rate, and convective heat flux distribution on the wall under different impact heights and nozzle diameter were calculated and compared. Meanwhile, the influence of different inlet flow rates on cooling performance was also calculated. The results show that when the nozzle radius is $2 \mathrm{~mm}$, the impact height is $4 d$, and the inlet flow velocity is $35 \mathrm{~m} / \mathrm{s}$, and the vertical jet impact method can achieve better cooling effect.

(4) Based on the analysis results of vertical jet impact modeling, the moving heat sink model was established, and the cooling effect under different heat sink-heat source distances was calculated by combining the calculated jet model parameters. The results show that the cooling time is shortened by $12.5 \%$ when the distance is $7 \mathrm{~mm}$. The welding experiment further validates the effectiveness of the vertical jet impact cooling method. The research results have guiding significance for improving the welding process of ultrathin compressor blades.

\section{Notations}

$\mu_{t} / \mu$ : Turbulent viscosity ratio, which is proportional to the Re

$C_{1 \varepsilon}: \quad$ Empirical constant

$C_{2 \varepsilon}: \quad$ Empirical constant

$G_{k}: \quad$ Turbulent energy generation

$\rho: \quad$ Density of argon

$u$ : $\quad$ Velocity component of argon in $x$ direction

$v$ : Velocity component of argon in $y$ direction

$w: \quad$ Velocity component of argon in $z$ direction

$V: \quad$ Argon velocity vector

F: $\quad$ Volume force of the microelement

$p: \quad$ Surface force of the microelement

$[\varepsilon]$ : $\quad$ Fluid deformation tensor

$D V / D \tau$ : Total derivative of the velocity vector to time

$\eta: \quad$ Dynamic viscosity

$F_{x}$ : $\quad$ Component of the volume force in the direction of $x$

$F_{y}$ : $\quad$ Component of the volume force in the direction of $y$

Fz: $\quad$ Component of the volume force in the direction of $z$

$t: \quad$ Thermodynamic temperature of the fluid

$S_{T}: \quad$ Viscous dissipation term 


$\begin{array}{ll}u_{\infty}: & \text { Initial velocity of the argon center } \\ v: & \text { Dynamic viscosity } \\ a: & \text { Thermal diffusion coefficients of the fluid } \\ \delta(x): & \text { Boundary layer thickness of the fixture surface } \\ & \text { velocity from the front end } x \\ \delta_{T}: & \text { Thickness of the thermal boundary layer } \\ k: & \text { Thermal conductivity of argon } \\ l: & \text { Characteristic length of the air domain } \\ r: & \text { Cooling radius } \\ d: & \text { Nozzle diameter. }\end{array}$

\section{Data Availability}

All data generated or analyzed during this study are included in this article.

\section{Conflicts of Interest}

The authors declare that they have no conflicts of interest.

\section{Acknowledgments}

The authors thank the Joint Fund for Civil Aviation of China (U1633104), China Civil Aviation Science and Technology Major Project (MHRD2013004), National Key Research and Development Project of China (2019YFB1311104), and Natural Science Foundation of Hebei Province of China (F2017202243) for the support in this study.

\section{References}

[1] C. Qiao, J. Li, B. Yang et al., "Influence of shape of foreign objects on impact damage of aero-engine compressor rotor blades," Chinese Journal of Applied Mechanics, vol. 31, no. 6, pp. 825-829, 2014.

[2] H. Liu, H. Chen, W. Liu et al., "Numerical analysis of flowthermal coupling in micro-plasma welding pool of thin-wall part," China Welding, vol. 27, no. 2, pp. 13-18, 2018.

[3] A. Wang, J. He, and L. Y. Pei, "The dynamic distribution characteristics of optical radiation intensity of pulsed microbeam plasma arc welding arc," Transactions of the China Welding Institution, vol. 37, no. 7, pp. 70-74, 2016.

[4] W. Wang, L. Yao, H. Yaxin et al., "Effect of forced cooling on microstructure and properties of TC4 titanium alloy friction stir welded joints," Rare Metal Materials and Engineering, vol. 44, no. 11, pp. 2842-2846, 2015.

[5] F. Karimzadeh, A. Ebnonnasir, and A. Foroughi, "Artificial neural network modeling for evaluating of epitaxial growth of Ti6Al4V weldment," Materials Science and Engineering A, vol. 432, no. 1-2, pp. 184-190, 2006.

[6] M. Baruah and S. Bag, "Influence of heat input in microwelding of titanium alloy by micro plasma arc," Journal of Materials Processing Technology, vol. 231, pp. 100-112, 2016.

[7] R. S. Desai and S. Bag, "Influence of displacement constraints in thermomechanical analysis of laser micro-spot welding process," Journal of Manufacturing Processes, vol. 16, no. 2, pp. 264-275, 2014.

[8] V. Manvatkar, A. De, L.-E. Svensson, and T. DebRoy, "Cooling rates and peak temperatures during friction stir welding of a high-carbon steel," Scripta Materialia, vol. 94, pp. 36-39, 2015.
[9] J. Sun, J. He, and D. Deng, "Numerical simulation of the influence of forced cooling on the temperature field of electroslag welding joint," Transactions of the China Welding Institution, vol. 37, no. 1, pp. 63-132, 2016.

[10] W. Chunhua, Research on Mechanical Properties of Laser Welded Joints and Local Cooling Assisted Welding Process, Huazhong University of Science and Technology, Wuhan, China, 2015.

[11] S. G. K. Manikandan, D. Sivakumar, K. Prasad Rao, and M. Kamaraj, "Microstructural characterization of liquid nitrogen cooled Alloy 718 fusion zone," Journal of Materials Processing Technology, vol. 214, no. 12, pp. 3141-3149, 2014.

[12] S. G. K. Manikandan, D. Sivakumar, K. P. Rao, and M. Kamaraj, "Effect of weld cooling rate on Laves phase formation in Inconel 718 fusion zone," Journal of Materials Processing Technology, vol. 214, no. 2, pp. 358-364, 2014.

[13] I. Khalil, R. Hayes, Q. Pratt, C. Spitler, and D. Codd, "Experimental and numerical modeling of heat transfer in directed thermoplates," International Journal of Heat and Mass Transfer, vol. 123, no. 123, pp. 89-96, 2018.

[14] W. Fan, S. Ao, Y. Huang et al., "Water cooling keyhole gas tungsten arc welding of HSLA steel," International Journal of Advanced Manufacturing Technology, vol. 92, no. 6, pp. 1-10, 2017.

[15] H. G. Sun and W. J. Huo, "Aeroengine turbine blade repair technology," Aviation Maintenance, vol. 6, pp. 12-13, 2001.

[16] R. J. Bai and L. G. Zhang, "Turbine blade repairing and its market analysis," Aviation Manufacturing Technology, vol. 12, pp. 37-40, 2002.

[17] H. Wang, L. Wang, T. Wang et al., "Method and implementation of remanufacturing and repair of aircraft engine damaged blade," Acta Aeronautica et Astronautica Sinica, vol. 37, no. 3, pp. 1036-1048, 2016.

[18] M. Gong, S. Dai, P. Jia, D. Wang et al., "Heat transfer modeling and cooling method for aeroengine blade MPAW Repair," Transactions of the China Welding Institution, vol. 40, no. 7, pp. 24-30, 2019.

[19] Y. Li, L. Ma, Z. Jiang et al., "Temperature field analysis of roll heated by fluid-solid coupled heat transfer," Journal of Mechanical Engineering, vol. 54, no. 24, pp. 51-60, 2018.

[20] F. R. Menter, "Two-equation eddy-viscosity turbulence models for engineering applications," AIAA Journal, vol. 32, no. 8, pp. 1598-1605, 1994.

[21] V. Yakhot and S. A. Orszag, "Renormalization group analysis of turbulence. I. Basic theory," Journal of Scientific Computing, vol. 1, no. 1, pp. 3-51, 1986.

[22] A. A. El-Hadj and N. Ait-Messaoudene, "Comparison between two turbulence models and analysis of the effect of the substrate movement on the flow field of a plasma jet," Plasma Chemistry and Plasma Processing, vol. 25, no. 6, pp. 699-722, 2005.

[23] J. Wang and $\mathrm{H} . \mathrm{Xu}$, "Numerical simulation of flow around baffles based on different turbulence models," Journal of Jiangsu University (Natural Science Edition), vol. 41, no. 1, pp. 27-33, 2020. 